\title{
TENSE BEYOND THE VERB: ENCODING CLAUSAL TENSE/ASPECT/MOOD ON NOMINAL DEPENDENTS *
}

\author{
RACHEL NORDLINGER
}

LOUISA SADLER

\begin{abstract}
It is generally held that clausal temporal, aspectual and modal features, when encoded morphologically, are expressed by or on clausal heads. However nominals and modifiers within NP can also be inflected for tense, aspect and modal features interpreted with respect to the clausal predication rather than with respect to the nominal argument itself. Such nominals (and dependents within NP) therefore contribute syntactic tense, aspect and mood features to the clause, but do not themselves have syntactically active TAM features. Building on previous work we show how a simple account of this phenomenon can be given in the lexicalist, constraint-based theory of LFG. In particular, the use of inside-out function application in LFG permits us to capture directly the role of nominal morphology in defining clausal TAM properties without recourse to derivational or feature passing mechanisms.
\end{abstract}

\section{Introduction}

A standard assumption in linguistic theory is that features relevant to the clause as a whole are associated with a clausal head. In more concrete terms, this translates into the assumption that clausal features such as tense/aspect $/ \mathrm{mood}$ (henceforth TAM) are encoded by verbs, verb-like auxiliary elements or particles. Indeed, some go so far as to assert that this association is universally true, that is, that no language expresses tense through nominal morphology:

We begin by answering the immediate objection that the existence of diversity invalidates arguments for universal language design....[T]hough grammatical devices are put to different uses in different languages, the possible pairings are very circumscribed. No language uses noun affixes to express tense [emphasis added - RN \& LS] or elements with the syntactic privileges of auxiliaries to express the shape of the direct object" Pinker and Bloom (1990, p. 715).

* For helpful discussion and data we are grateful to Sasha Aikhenvald, Doug Arnold, Claire Bowern, Joan Bresnan, Mary Dalrymple, Matthew Dryer, Nick Evans, Hitomi (Mimmi) Ono, Andrew Radford, Ivan Sag, Andrew Spencer, Judith Tonhauser, and audiences at LFG00, the Essex-Tübingen Claire workshop and the San Diego workshop on paradigms and periphrasis, and also to subscribers to the LINGTYP list. Thanks also to Peter Culicover and three anonymous NLLT reviewers for many constructive and insightful comments. A very preliminary version of this work appears as Nordlinger and Sadler (2000). Rachel Nordlinger would like to acknowledge the financial support of the Australian Research Council (APD F9930026) held at the University of Melbourne, and Louisa Sadler a period of sabbatical leave from the University of Essex.

(C) 2003 Kluwer Academic Publishers. Printed in the Netherlands.

c044ns.tex; 27/11/2003; 11:15; p.1 
However, this assumption is incorrect. In many languages dependent nominals and nominal modifiers may also be inflected for tense, aspect and mood interpreted with respect to the clausal predication. ${ }^{1}$ For example, in Chamicuro (Arawak, Peru), the definite article encodes a (clausal) past/non-past tense distinction, independently of the verb (which usually has no tense marking at all) (Parker, 1999). Note that in (1a, b) the definite article is encliticized phonologically to a consonant-final preceding element, for reasons internal to the language's phonology. Parker (1999) argues convincingly that this is purely phonological cliticization and thus that the article is an independent NP constituent, and not incorporated morphologically into the preceding verb. This is demonstrated by the contrast with $(1 \mathrm{c}, \mathrm{d})$ in which the preceding verb is vowel-final. Note further that in any case, the preceding element is not always a verb. ${ }^{2}$

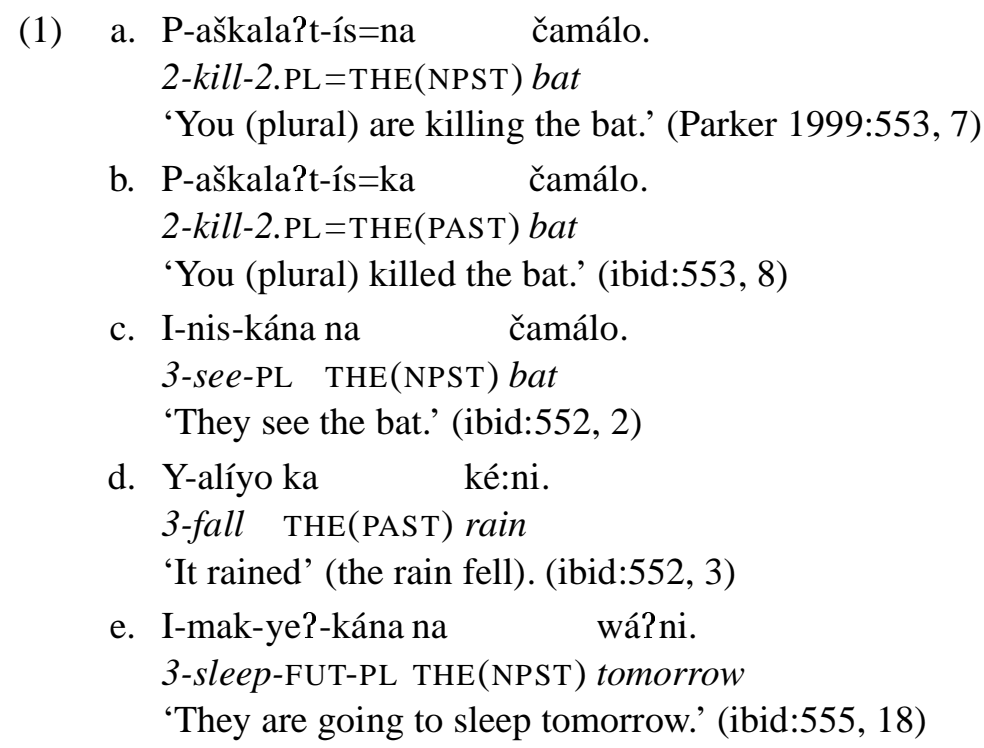

In other languages, the same tense and aspect affixes which appear on verbs may also appear on dependent nominals. In Sirionó (Tupí-Guaraní, Bolivia) suffixes marking clausal tense and aspect may be found on the verb, on a dependent nominal, or on both (Firestone, 1965). In example (2a) the verb alone is inflected for both past tense and perfective aspect, in (2b) past tense is marked on the nominal and perfective aspect on the verb and in (2c) perfective aspect is 'doubly-marked', appearing on the object noun as well as the verb. Note that Firestone (1965) provides extensive argumentation for the view that these tense/aspect markers are indeed affixes rather than syntactic elements.

\footnotetext{
${ }^{1}$ For reasons of space, we exemplify the phenomenon here with only a subset of languages; for the full range of languages with such TAM-marked NPs see Nordlinger and Sadler (2002).

${ }^{2}$ A reviewer notes that it would be best to have contrasting examples for all tenses with the same verb, but unfortunately these are not provided in the source.
} 
(2) a. Áe ií osó-ke-rv.

he water go-PAST-PERF

'He went to the water.' (Firestone 1965:35)

b. jýkv-ke úke-rv. tiger-PST sleep-PERF

'The tiger slept.' (ibid:35)

c. Áe osó-ke-rv ií-rv.

he go-PAST-PERF water-PERF

'He went to the water.' (ibid:35)

And in Lardil, a Tangkic (non-Pama-Nyungan) language from northern Australia, most non-subject constituents are inflected with case/tense portmanteau suffixes which vary according to the tense category of the verb (Klokeid 1976, Hale 1998): ${ }^{3}$

(3) a. Ngada bilaa wu-thur ngimbenthar diin-kur

1SG.NOM tomorrow give-FUT 2SG.FOBJ this-FOBJ

wangalk-ur.

boomerang-FOBJ

'I'll give you this boomerang tomorrow.' (Klokeid 1976:493)

b. Ngada niwentharr maarn-arr wu-tharr.

1SG.NOM 3SG.NFOBJ spear-NFOBJ give-NFUT

'I gave him a spear' (ibid:476)

The primary purpose of this paper is to demonstrate how this phenomenon of encoding clause-level TAM features on dependent NPs can be given a natural and unified analysis using the model of constructive morphology developed in Nordlinger (1998) within the framework of Lexical-Functional Grammar (LFG), and in particular the association of so-called inside-out descriptions with words. This work builds on and extends this previous work on constructive morphology on several levels. Firstly we provide extensive further motivation for the approach from a range of languages from diverse linguistic types. Secondly we show that the phenomenon is not limited to case markers in temporal function (data of the sort treated in Nordlinger's previous work), but extends to

\footnotetext{
${ }^{3}$ It is not clear to us why the temporal NP bilaa 'tomorrow' in (3a) does not have future case/tense marking in this example, since Klokeid provides other similar examples in which this NP is so inflected:
}

(1) Ngada kudi-thur kentapal-ur pilaan-kur. 1SG.NOM see-FUT dugong-FOBJ tomorrow-FOBJ 'I'll see a dugong tomorrow.' (Klokeid 1976: 413) 
include a wide variety of morphological exponents, including the use of 'verbal' TAM affixes on nominals, and cases in which the encoding of clausal TAM features occurs on determiners, or on pronouns alone. As we will see, the constructive morphology approach, developed in the treatment of Australian case marking, extends directly without further refinement to account for all these cases. Thirdly, we show how in some languages, the association of clausal TAM information with nominals deeply embedded within the clause can be straightforwardly and directly captured by the use of inside-out functional uncertainty statements. Finally, we consider some cases which seem to involve a finite element, which would otherwise be the head of the clause, incorporating morphologically into a clausal dependent, that is, true head incorporation as opposed to the (simple!) incorporation of features of the head. Our analysis is presented in section 2 , and is followed by a discussion of other theoretical approaches to such phenomena in section 3. In the remainder of this section, however, we discuss the many interesting theoretical issues raised by the phenomenon of dependentencoded clausal TAM, of relevance to any formal syntactic framework.

Firstly, in these languages we find clausal information encoded on dependent nominals and other NP constituents, contrary to the normal assumption that clausal information is associated with the heads of clauses (and/or co-heads or functional categories associated with the verb, such as auxiliaries and particles). Furthermore, as a consequence of this, such tense-inflected nominals are encoded with information that is not relevant to their own semantic interpretation; they are morphologically tensed without being temporally located. As such this phenomenon appears to constitute a counter-example to Bybee's principle of relevance which predicts that a semantic element will only have inflectional expression if its meaning is "highly relevant" to the stem to which it attaches (Bybee, 1985, p. 13). Consider, for example, the Sirionó example in (2b) above. Here, the object NP morphologically encodes the past tense. However, the semantic predicate over which this past tense has scope - the predicate which is to be temporally located in the past - is not that of the NP ('tiger'), but that of the whole proposition ('the tiger sleeping'). The semantics associated with this example, then, can be informally represented as in (4a), and crucially not as in (4b).

$$
\begin{aligned}
& \text { a. tiger }(\mathrm{x}) \&[\operatorname{PAST}(\operatorname{sleep}(\mathrm{x}))] \\
& \text { b. }[\operatorname{PAST}(\operatorname{tiger}(\mathrm{x}))] \& \text { sleep }(\mathrm{x})
\end{aligned}
$$

This contrast between temporal location of the clause and the NP can be illustrated most clearly by contrasting the languages we are focussing on here with those in which we find morphological encoding of tense on nominals where

\footnotetext{
${ }^{4}$ Leaving aside for the moment the semantics of the perfective aspect marker, which is more standardly affixed to the clausal head in this example.
} 
the nominal is itself temporally located. ${ }^{5}$ Consider the following examples from Tariana (Arawak, Brazil) (Aikhenvald to appear):

(5)

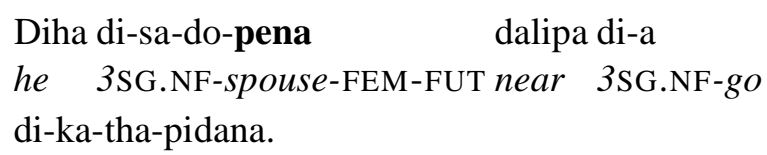

(6) pi-ruku pi-uka hi 2SG-come.down 2SG-arrive DEM:ANIM

panisaru-miki-ri-naku pira pi-katha-nha. abandoned.village-PST-NF-TOP.NON.A/s 2SG.order 2SG-vomit-IMP

'When you come to an abandoned ex-village, order (him) to vomit.'

Tariana has two nominal tense suffixes - -pena 'FUT' and -miki 'PST'. Unlike the other examples of nominal tense illustrated earlier, these tense markers do not encode the tense of the clause, but rather temporally locate the nominal itself (or, more accurately, the time at which the property denoted by the nominal holds of the referent). In (6), for example, the past tense marker on panisaru 'abandoned village', encodes the fact that the time at which the property of being a village holds of the referent is in the past (i.e. 'ex-village, former village'). That this nominal tense system is distinct from that encoding clausal tense is shown by the fact that the two need not agree in temporal value: in (5), for example, the noun $s a$ 'spouse' is marked with the future tense, while the clause as a whole is marked with the 'remote past, reported evidentiality' clitic -pidana.

There is, therefore, a clear semantic contrast between non-propositional nominal tense and the phenomenon of nominal-marked clausal tense, despite the fact that both are morphologically encoded on nominals. This distinction has important implications for a theoretical analysis of nominal tense marking, since any complete syntactic analysis will need to distinguish between nominal tense which is intrinsic to the NP itself, and that which is morphologically associated with the nominal but semantically interpreted with respect to the clause.

That these nominals are encoded with clause-level TAM also raises the related theoretical issue of how the TAM is to come to be associated with the clause at all. It is generally assumed in most theoretical frameworks that clause-level features percolate in some way through head chains (verbal projections and functional projections appropriate for verbs) and not through argument NPs (e.g. Haegeman (1994, pp. 108-123)). However, there are some languages in which the TAM marking on dependent NPs is the sole TAM marking for the clause; in these cases

\footnotetext{
${ }^{5}$ In Nordlinger and Sadler (to appear) this is referred to as 'independent nominal tense'.
} 
the TAM information for the clause is provided only by a dependent NP. Consider again the following examples from Chamicuro, repeated from above. ${ }^{6}$
a. P-aškala?t-ís=na čamálo.
2-kill-2. PL =THE(NPST) bat
'You (plural) are killing the bat.'
b. P-aškala?t-ís=ka čamálo.
2-kill-2. PL=THE(PAST) bat
'You (plural) killed the bat.'

In both of these examples the verb appears in the same form, unmarked for tense. Instead, the past/nonpast tense contrast is encoded solely via the tensemarked determiners embedded within the object NPs. Any formal treatment of Chamicuro, therefore, needs to enable the tense information encoded by an argument NP to percolate directly to the clause, independently of the verb (since the verb is not marked for tense itself). Assuming that the verb in these examples contains some unexpressed or 'invisible' tense feature with which the tenseddeterminers agree isn't plausible since verbs in Chamicuro can optionally inflect for tense themselves (8):

(8) i-ṣ̆wisyo-kana-kati paspatal-musta.

3-come.down-PL-PST raft-WITH

'They came down (the river) by raft.' (ibid:556, 23)

Different theoretical challenges are raised by languages in which the TAMmarking on dependent NPs interacts in some way with the TAM-marking on the verb. Consider again the Lardil examples repeated here from above.

(9) a. Ngada bilaa wu-thur ngimbenthar diin-kur lSG.NOM tomorrow give-FUT 2SG.FOBJ this-FOBJ wangalk-ur.

boomerang-FOBJ

'I'll give you this boomerang tomorrow.'

b. Ngada niwentharr maarn-arr wu-tharr.

1SG.NOM 3SG.NFOBJ spear-NFOBJ give-NFUT

'I gave him a spear.'

There is a general requirement in Lardil that when the verb is inflected with either the future (9a) or non-future (9b) tense suffix all non-subject NPs in the clause must usually carry tense marking in agreement. The fact that Lardil

\footnotetext{
${ }^{6}$ Recall that in (7), the definite article is encliticized phonologically to a consonant-final preceding element, but is syntactically part of the object NP.

7 Note that there is third verbal form, termed the 'plain' or 'general non-future' form by Hale (1997), which does not trigger agreement on clausal dependents. We return to this issue in section 3 below.
} 
verbs and dependents agree in clausal TAM features in this way challenges the claim by Lehmann and Moravscik $(2000,742)$ that "tense is not an agreement category". This type of agreement is in fact the reverse of what is usually expected between a verb and its dependents since it involves properties of the clausal head (i.e. clausal TAM) being marked on clausal dependents, rather than the more usual circumstance of properties of clausal dependents being reflected morphologically in the clausal head (as with subject-verb agreement, for example). Instead, the agreement between the Lardil verb and its dependent NPs is more like noun-adjective concord, in which adjectival modifiers are marked to agree with inherent features of the head noun (e.g. gender, number, case) ${ }^{8}$

The situation becomes even more complicated in the closely related language Kayardild, where there is a mismatch between the TAM information contributed by the verb and the NP dependents. In Kayardild, all non-subject NPs must be inflected with modal case which, along with the TAM information associated with the verb, encodes TAM features for the clause as a whole. Crucially, however, the clausal TAM features arise as a composite of the information contributed by the verbal and nominal TAM inflections (Evans, 1995). Consider the following examples.

(10) Ngada kurri-nangku mala-wu (balmbi-wu). 1SG.NOM see-NEG.POT sea-M.PROP morrow-M.PROP

'I won't be able to see the sea (tomorrow).' (Evans1995:404, 10-12)

(11) Ngada kurri-nangku mala-y (barruntha-y).

1SG.NOM see-NEG.POT sea-M.LOC yesterday-M.LOC

'I could not see the sea (yesterday).' (ibid, 10-13)

In these examples the verbal inflection remains constant; it is only through the variation in modal case ('modal proprietive' vs. 'modal locative') that the clausal tense/mood distinction is encoded. The 'negative potential' verbal inflection is used here with its meaning of 'inability': combining with the "future" meaning of the modal proprietive case marker in (10) places this inability in the future, while combining with the "instantiated" meaning of the modal locative in (11) expresses that there was a real occasion, yesterday, when the inability existed (Evans 1995, p. 404). The theoretical challenge raised by the Kayardild data is that, not only do dependent NPs reflect what would usually be considered to be categories of the head, but the values introduced by dependent and head do not match. Thus, an attempt to treat this phenomenon as an instance of 'spreading' or 'feature copying' would be unsustainable.

More challenging again is the fact that in some languages the TAM-marked dependent can be deeply embedded within the clause whose TAM value it marks,

\footnotetext{
${ }^{8}$ See Evans (2003) for detailed discussion of the implications of this tense agreement in Lardil and Kayardild for typologies of agreement.
} 
thereby constituting examples of long distance agreement. In Supyire (NigerCongo, Mali), for example, first and second person pronouns encode a distinction between declarative and non-declarative mood for the clause (Carlson, 1994). ${ }^{9}$ This distinction is encoded on all pronominal forms, irrespective of their grammatical function e.g. as subject, objects or possessors. The following examples are typical.

a. Mìi à pa.

I PERF come

'I have come.' (Carlson 1994:152, 1b)

b. Mu a mì̀ kánhá.

You PERF me tire

'You have annoyed me.' (ibid:152, 2b)

a. $\mathrm{Na}$ wì̀.

me.NONDECL look.at

'Look at me.' (imperative) (ibid:154, 7a)

b. Na cevoo `ykùu, taá ma kéćgé ke?

my. NONDECL friend chicken where you.NONDECL go.IMPV LOC.Q

'My friend chicken, where are you going?' (ibid, 7c)

In (12a) and (12b) the first person pronoun mii functions as subject and object respectively of a declarative clause. In (13a) we see the use of the nondeclarative form $n a$ marking the object of an imperative clause. In (13b) this same non-declarative pronoun functions as a possessor, embedded within the vocative NP.

Tense agreement is also extended to embedded possessors in Lardil (and Kayardild). Consider the following example in which the possessor of the instrumental NP niwen-kur- $u$ carries not only instrumental case in agreement with its nominal head, but also tense in agreement with the head of the clause to which the larger instrumental NP belongs.

(14) Ngada marndi-thu niwentha niwen-kur-u

1SG.NOM rob-FUT 3SG.FOBJ 3SG.GEN-INSTR-FOBJ

kerndi-wur-u.

wife-INSTR-FOB J

'I will steal his wife for him.' (Hale 1997:201)

Such data would appear to (further) preclude an analysis in which dependentmarked TAM is treated as a type of concord with the verb. Concord relations are

\footnotetext{
${ }^{9}$ Carlson (1994, p. 153) states that declarative pronouns can also be used in non-declarative contexts. Following Carlson's own practice, we refer to these forms as declarative while omitting DECL from the interlinear glossing.
} 
necessarily local, yet in these languages clause-level TAM features are encoded not only on clausal dependent NPs, but on dependents of those dependents (and so on) as well. Crucially, in the case of Supyire, distinctions of mood are made only in the pronominal system, and treating this as an instance of (local) featural concord would require us to postulate the mood features for every phrasal node on the path between the "controlling" verbal head, and the embedded pronominal, irrespective of the fact that these features are never overtly instantiated on the heads of those intervening phrasal projections.

In the remainder of this paper, building on previous work in Nordlinger 1998 (see also Sadler 1998 and Nordlinger and Sadler 2000), we provide an analysis of this phenomenon in LFG which addresses all of these larger theoretical issues. We argue that this data can be straightforwardly accounted for by an approach in which clause-level TAM information may be directly contributed by nominal constituents. We show how the correspondence architecture of LFG, and particularly the constructive morphology approach currently being developed within $\mathrm{it}^{10}$, permits a simple and natural analysis of these data. A crucial aspect of this analysis is that it does not postulate (empty or vacuous) syntactic TAM features in the nominal syntactic structure, or rely on configurational assumptions which are not transparently motivated with respect to the language in question, but rather enables dependent nominals to contribute information directly to the syntactic structure of the clause. This approach not only provides an explanatory account for the cross-linguistic phenomenon of TAM-inflected dependent NPs, but also highlights one of the strengths of the flexible, correspondence-based architecture of LFG.

\section{An LFG Analysis}

\subsection{THE FRAMEWORK}

Lexical-Functional Grammar (LFG) (Bresnan 1982, Kaplan and Bresnan 1982, Dalrymple et. al. 1995, Bresnan 2001, Falk 2001, Dalrymple 2001) is a nonderivational lexicalist constraint-based theory with co-present parallel structures, linked by principles of correspondence. Each of the structures of LFG has a distinct formal character and models a different aspect of the structure of language. The primary syntactic structures are c-structure (constituent structure) and fstructure (functional structure). The former models precedence and phrasal dominance relations in the familiar terms of a phrase structure tree and the latter models predicate-argument relations in terms of grammatical functions. Formally, f-structures are finite functions from attributes to values, which may themselves be complex (i.e. f-structures), and they are conventionally represented

\footnotetext{
${ }^{10}$ See Nordlinger (1998), Sadler (1998), Barron (1998), Lee (1999), Sharma (1999), Nordlinger and Sadler (2000), Sells (2000), O'Connor (2002), Ørsnes (2002), among others.
} 
as attribute-value matrices. Equations (known as functional (f-) descriptions) associated with lexical items and with nodes of the c-structure specify properties of f-structures: the mapping function or projection $\phi$ has nodes of the c-structure as its domain and f-structures as its range (the inverse $\phi^{-1}$ maps f-structures to c-structures): the notation $\uparrow$ refers to the f-structure associated with the mother of the current node (i.e. it denotes the mother's f-structure) while $\downarrow$ refers to the f-structure of the node to which it is annotated. Feature assertions are satisfied by f-structures which contain attribute-value pairs corresponding to these assertions. Of particular importance is the smallest f-structure which satisfies a collection of constraints or feature assertions, known as the minimal model. The f-structure of an utterance is the minimal model or solution satisfying the constraints introduced by the words and phrases in the utterance.

The formal correspondence between c-structure and f-structure is many-toone: to each c-structure node there is assigned a unique (but not necessarily distinct) (minimal) f-structure. Nevertheless individual c-structure elements, including words, may specify complex f-structures. For example, sees in (15), which will associate with a single node $\mathrm{V}$ in c-structure, defines the f-structure shown in (16).

$$
\begin{aligned}
& \text { sees: }(\uparrow \text { PRED })=\text { 'SEE }\langle(\uparrow \mathrm{SUBJ})(\uparrow \mathrm{OBJ})\rangle \text { ' } \\
& (\uparrow \quad \text { TENSE })=\text { PRES } \\
& (\uparrow \quad \text { SUBJ })=\downarrow \\
& (\downarrow \text { PERS })=3 \\
& (\downarrow \mathrm{NUM})=\mathrm{SG} \\
& {\left[\begin{array}{ll}
\text { PRED } & \text { 'SEE }\langle(\text { SUBJ })(\text { OBJ })\rangle ’ \\
\text { TENSE } & \text { PRES } \\
\text { SUBJ } & {\left[\begin{array}{ll}
\text { PERS } & 3 \\
\text { NUM } & \text { SG }
\end{array}\right]}
\end{array}\right]}
\end{aligned}
$$

An important facet of LFG is its commitment to lexicalism. The Lexical Integrity Principle (17) (see Simpson 1983, Bresnan and Mchombo 1995, Mohanan 1995, and references therein) distinguishes the morphological (lexical) and syntactic components as being subject to different principles of composition. Words are constructed in the morphology, while c-structure and f-structure form the core of the syntactic component. This means that the input to these syntactic levels-e.g. the terminal elements of c-structure trees-are fully inflected words, and that syntactic processes cannot manipulate the internal morphological structure of these items. Crucially however, this does not rule out the possibility that both morphological and syntactic constituents may contribute the same types of information to the f-structure (e.g. Simpson 1983, 1991, Bresnan 
and Mchombo 1987, 1995, Bresnan 2001). The Lexical Integrity Principle is stated as follows (from Bresnan 2001):

\section{(17) Lexical integrity:}

Morphologically complete words are leaves of the c-structure tree and each leaf corresponds to one and only one c-structure node.

Given the flexibility of the LFG architecture, it is not necessary to postulate otherwise unmotivated c-structure nodes in morphologically rich languages where the morphology directly encodes much f-structure or relational information. Indeed the Principle of Economy of Expression states that all syntactic nodes are optional unless otherwise required for the satisfaction of semantic expressivity or other independent principles (Bresnan 2001).

A variety of wellformedness conditions are required to hold of f-structures. In particular, the principles of completeness and coherence require that all the arguments of a predicate occur in the f-structure and that no additional arguments occur. The subcategorised arguments of a predicate are specified in its PRED value (see (15) above), which additionally distinguishes thematic arguments (inside the angle brackets) from non-thematic arguments (outside the angle brackets). A governable grammatical function is one which can be subcategorised for by a predicate (for example, SUBJ, OBJ, OBL).

(18) An f-structure is locally complete if and only if it contains all the governable grammatical functions that its predicate governs. An f-structure is complete if and only if it and all its subsidiary f-structures are locally complete (Dalrymple 2001:37)

(19) An f-structure is locally coherent if and only if all the governable grammatical functions that it contains are governed by a local predicate. An f-structure is coherent if and only if all its subsidiary f-structures are locally coherent (Dalrymple 2001:39)

In f-descriptions, LFG provides a rich and flexible formalism for talking about $\mathrm{f}$-structures. This includes functionally uncertain constraints, that is, equations which make use of regular expressions and abbreviatory symbols over grammatical function names to denote sets of paths through an f-structure, first used in the description of long distance dependencies. Consider for example whquestions in English, in which a fronted wh-element may correspond to a within clause function deeply embedded within the clause. The grammatical function corresponding to a fronted wh-question word in LFG is the FOCUS function. A possible functional annotation to capture English question formation might therefore be the following (Dalrymple 2001, p. 141):

$$
\begin{array}{cc}
\text { XP } & C^{\prime} \\
(\uparrow \text { FOCUS })=\downarrow & \uparrow=\downarrow \\
(\uparrow \text { FOCUS })=(\uparrow\{\text { XCOMP } \mid \text { COMP }\} * \text { GF }) &
\end{array}
$$


The regular expression $\{\mathrm{XCOMP} \mid \mathrm{COMP}\} *$ stands for paths containing any number of XCOMP or COMP attributes, and GF stands for any grammatical function. Thus, the f-description ( $\uparrow$ FOCUS $)=(\uparrow\{$ XCOMP $\mid$ COMP $\} *$ GF) states that the f-structure of the FOCUS attribute of the f-structure denoted by $\uparrow$ is identified with (i.e. is one and the same f-structure as) the f-structure of an unspecified grammatical function at the end of a path consisting of any number (including zero) of XCOMP or COMP attributes. It therefore accounts for an example as in (21a), in which the 'gap' is embedded in a single COMP as well as that in (21b), where the path to the within clause function is COMP ХCOMP OBJ.

a. What does Kim think Peter bought?

b. What does Kim think Peter expected Mary to buy?

\subsection{Constructing Dependent-Encoded TAM}

An account of dependent NPs inflected with clausal TAM follows naturally within the constructive morphology approach of LFG. Constructive morphology makes use of a further type of constraint, the inside-out expression (c.f. Halvorsen and Kaplan 1988, Dalrymple 1993, see also Andrews 1996, pp. 41-43), associated with the lexical elements or morphological processes to enable nominal constituents to define the larger syntactic (f-structure) context in which they are enclosed. ${ }^{11}$ The model of constructive morphology (that is, the use of insideout function application in the morphology) is most developed in Nordlinger's (1998) analysis of case marking in Australian languages. In this approach, casemarked nominals specify the grammatical function of the higher clause of which their f-structure is the value. Thus the f-structure information associated with accusative case is as in (22), and an accusative-case nominal (e.g. 'tiger-ACC') specifies the f-structure in (23). ${ }^{12}$

$$
\begin{aligned}
\text { ACC: } & (\uparrow \mathrm{CASE})=\mathrm{ACC} \\
& (\mathrm{OBJ} \uparrow)
\end{aligned}
$$

\footnotetext{
11 Inside-out function application is well-established in LFG through work on a large number of diverse phenomena, including quantifier scope (Halvorsen and Kaplan 1988), anaphoric binding (Dalrymple 1993), internally-headed relative clauses (Culy 1990), the treatment of the Russian genitive of negation (King 1995), Urdu case (Butt 1995), case in Australian Aboriginal languages (Nordlinger 1998), and topicalization (Bresnan 2001).

12 Nordlinger (1998) uses a morpheme-based morphology for expository convenience, but the basic principles of the constructive case model are independent of whether one assumes that such case information is associated with morphemes (form-function pairs) or with morphological features (which are independently related to exponence in a realizational approach to morphology) or indeed with the morphological processes themselves which map (sets of) morphological features to phonological exponents. For a translation of Nordlinger's (1998) constructive case model into the realizational Paradigm Function Morphology (Stump, 2001), see Sadler and Nordlinger (2003). For ease of exposition, we follow Nordlinger (1998) in adopting a morphemic "shorthand" here.
} 
(23)

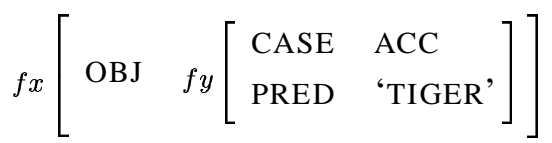

By virtue of the inside-out designator (OBJ $\uparrow$ ), the information associated with the accusative case constructs a higher f-structure $(f x)$ which contains an OBJ to which the immediate $\mathrm{f}$-structure containing the case-inflected nominal $(f y)$ belongs. Thus, on this analysis, a nominal inserted into the syntax already constructs its grammatical function by virtue of the case marker attached to it. ${ }^{13}$

For the purposes of this paper, the important aspect of the constructive case approach is that embedded nominals (such as those functioning as arguments or adjuncts of verb-headed clauses) can specify information about the higher fstructure to which they belong - in the accusative case examples above we see how a case-inflected nominal can specify its grammatical function in the higher clause. If such nominals can specify information about the higher clause, then there is no logical reason why they couldn't also provide other types of information to the clausal f-structure, such as information about clause-level TAM. Thus, the constructive case approach, independently motivated to account for many of the complexities of case marking in Australian (and other) languages, provides a simple and natural account of the use of clausal TAM on dependent nominals also.

Nordlinger (1998, pp. 122-123) demonstrates this use of constructive case with an analysis of case/tense portmanteaux in Pitta Pitta (Pama-Nyungan, Australia). The Pitta Pitta case system is summarised in Table I below (taken from Blake 1987, p. 59, Table 13), and exemplified by examples (24) - (27). As this shows, not only do case markers in Pitta Pitta encode a future/non-future tense distinction, but the case marking system itself differs according to the tense of the clause: future tense involves a nominative/accusative case distinction, and non-future a three-way distinction between intransitive subject (S), transitive subject $(\mathrm{A})$ and object $(\mathrm{O}) .{ }^{14}$

\footnotetext{
13 Inside-out expressions are defined as follows (Dalrymple, 2001, p. 145):

$(a, f)=g$ iff $g$ is an f-structure, $a$ is a symbol, and the pair $(a, f) \in g$

$(\epsilon, f) \equiv f$, where $\epsilon$ is the empty string

$(s$ a $f) \equiv(s(a f))$, for a symbol $a$ and a (possibly empty) string of symbols $s$

14 Blake (1979) does note however that the non-future object form -nha is used by some of his language consultants for future tense also, alongside the specifically future tense form $-k u$.
} 
Table I. Pitta Pitta case/tense suffixes

\begin{tabular}{|l|llll|}
\hline & $\mathrm{S}$ & $\mathrm{A}$ & $\mathrm{O}$ & \multicolumn{1}{l}{ Inst } \\
\hline Non-Future & $-\emptyset$ & - lu & -nha & -lu \\
Future & -ngu & -ngu & $-\mathrm{ku}$ & -ngu \\
\hline
\end{tabular}

(24) Ngamari karnta-ya ngartu-nga kankari-marru. mother(NFUT.NOM) go-PRES nardoo-PURP knife-having(NFUT.NOM) 'Mother's going for (to get) nardoo (edible plant species) with a knife.' (Blake 1987:59, 4.11)

(25) Ngamari-ngu karnta ngartu-nga kankari-marru-ngu. mother-FUT.NOM go nardoo-PURP knife-having-FUT.NOM 'Mother will go for (to get) nardoo with a knife.' (ibid:60, 4.13)

(26) Ngamari-lu ngunytyi-ka ngali-nha mother-NFUT.ERG give-PAST we.DU-NFUT.ACC mangarni-marru-nga-nha kathi-nha. bone-having-GEN-NFUT. ACC meat-NFUT. ACC. 'Mother gave us the doctor's meat.' (ibid, 4.12)

(27) Ngamari-ngu ngunytyi ngali-ku mother-FUT.NOM give we.DU-FUT.ACC mangarni-marru-nga-ku kathi-ku. bone-having-GEN-FUT.ACC meat-FUT.ACC.

'Mother will give us the doctor's meat.' (ibid, 4.14)

Note that these case/tense markers are also found on adjuncts modifying arguments, as in kankari-marru and kankari-marru-ngu in examples (24) and (25) respectively. According to Nordlinger's (1998) constructive case analysis, the information associated with the tense-marked accusative case markers, for example, is as follows:

$$
\begin{array}{lll}
\text { a. } & -n h a: \quad((\mathrm{OBJ} \uparrow) \mathrm{TNS})=\neg \mathrm{FUT} \\
& (\uparrow \mathrm{CASE})=\mathrm{ACC} \\
\text { b. } \quad-k u: \quad(\mathrm{OBJ} \uparrow) \mathrm{TNS})=\mathrm{FUT} \\
& (\uparrow \mathrm{CASE})=\mathrm{ACC}
\end{array}
$$

Nominals inflected with these cases, then, both specify their grammatical function in the higher f-structure and provide a tense feature for that higher f-structure, as shown by the f-structure corresponding to the future tense accusative suffix (28b) in (29): 


$$
f_{1}\left[\begin{array}{lll}
\text { TNS } & \text { FUT } & \\
\text { OBJ } & f_{2}[\text { CASE } & \text { ACC }
\end{array}\right]
$$

Nordlinger's primary concern is case marking, however this analysis of tensemarked dependent nominals is not inherently restricted to situations involving case. Thus, this general constructive approach extends simply and naturally to the range of TAM-inflected dependent NPs exemplified in section 1. To illustrate, we begin with an analysis of tense-marked determiners in Chamicuro.

As we saw in (1) above, in Chamicuro the definite article encodes distinctions of tense: $n a$ is the non-past (or present and future tense) definite article and $k a$ the past tense article. In contrast there is no obligatory tense morphology on verbs: there is no present tense marker, and the past and future tense markers (kati and -ye? respectively) are optional. Thus, in most examples, it is the definite marker alone which signals the tense information for the clause. The examples in $(1 \mathrm{c}, \mathrm{d})$ are repeated below:

$$
\begin{aligned}
& \text { (30) I-nis-kána na čamálo. } \\
& \text { 3-see-PL THE(NPAST) bat } \\
& \text { 'They see the bat.' } \\
& \text { (31) Y-alíyo ka ké:ni. } \\
& \text { 3-fall THE(PAST) rain } \\
& \text { 'It rained' (the rain fell). }
\end{aligned}
$$

Using the model of constructive morphology, the past tense definite article is associated with the following lexical description:

$$
\begin{array}{ll}
k a: & ((\mathrm{GF} \uparrow) \mathrm{TNS})=\mathrm{PAST} \\
& (\uparrow \mathrm{SPEC})=\mathrm{DEF}
\end{array}
$$

As noted above, the notation GF is conventionally interpreted in LFG as a variable over attribute names ranging over the set of grammatical functions (SUBJ, OBJ, OBL, etc). The first part of this lexical description therefore states that the definite article has some grammatical function in a higher f-structure (encoded by (GF $\uparrow)$ ) and that this higher f-structure has past tense. The second part contributes information to the f-structure of the definite article itself. ${ }^{15}$

This f-description thus places constraints both over the f-structure of the article and the immediately containing f-structure, as we saw in the discussion of Pitta Pitta above. That is, it describes the following partial f-structure:

\footnotetext{
15 Obviously if such a distinction were restricted to NPs in a particular grammatical function, this would be specified in the f-description (e.g. (SUBJ $\uparrow$ ) instead of (GF $\uparrow$ )). Such might be the case, for example, for English subject pronominals incorporating nonsyllabic reduced tense/mood markers: He'll be arriving at 10pm. See Spencer (1991), Barron (1998), Sadler (1998) and Bender and Sag (2001) for some discussion as to whether English has tensed pronominals.
} 


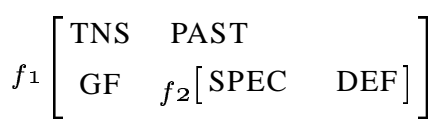

This f-description lexically associated with the definite article will interact with the information associated with the c-structure to define the actual grammatical function borne by the constituent containing the definite article.

For example, the c-structure and contribution of the NP in (34) is shown below. ${ }^{16}$ The subscripts $f 1, f 2$ etc. on the tree nodes serve only as an aid to the reader in identifying the corresponding f-structure. ${ }^{17}$

$$
\begin{aligned}
& \text { P-aškala?t-ís=ka čamálo. } \\
& \text { 2-kill-2.PL=THE(PAST) bat } \\
& \text { 'You (plural) killed the bat.' }
\end{aligned}
$$

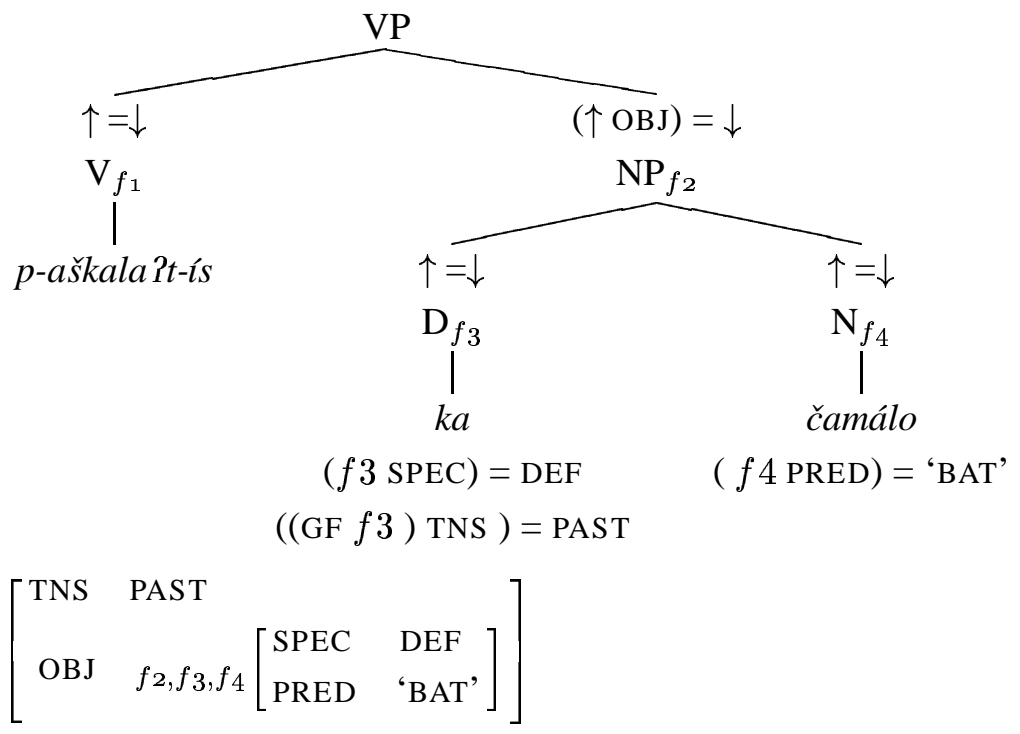

A crucial feature of this constructive morphology approach is that the tense information associated with dependent $\mathrm{NP}$ - here through the definite article - is placed into the outer (clausal) f-structure directly. It is not associated with the fstructure for the NP itself at all. Thus, this approach neatly captures the fact that these tense-marked dependent NPs are morphologically tensed without actually being semantically tensed; they carry tense information, but this is placed only into the f-structure of the clause as a whole. ${ }^{18}$

\footnotetext{
16 Recall that the cliticization of the definite article onto the preceding syntactic element is a purely phonological process.

17 For concreteness and in the absence of further evidence we assume the inflected verb is in V. Whether it is in V or in I is in fact immaterial to the mapping to f-structure. See Bresnan (2001) for the theory of extended heads and the c- to f-structure mapping.

18 This analysis of Chamicuro therefore complies exactly with Parker's (1999, p. 556) suggestion that the definite articles "are really tense markers themselves and their temporal features
} 
Moreover, since the tense information associated with the NP is placed directly into the clausal f-structure it is therefore required to be consistent (i.e unifiable) with any TAM information associated with the verb or other clausal head. Thus agreement between the tense information introduced by the definite article in Chamicuro and any tense information on the verb follows simply from the fact that verb and article both provide partial specification of the same fstructure, with no need for additional tense features in the f-structure of the NP itself nor extra stipulated constraints ensuring agreement between the tense of the NP and the verb. Clearly, if the values for the TENSE attribute specified by the verb and by a definite article, or by two definite articles, are inconsistent, then no satisfying f-structure will be constructed and the sentence is ungrammatical.

To illustrate further this interaction between NP-encoded tense and verbal tense, we turn to an analysis of the non-past definite article in Chamicuro. Parker (1999) describes this as being essentially ambiguous between present tense and future tense readings (rather than simply encoding a nonpast value for tense). This article may co-occur with overt future tense marking on the verb, as in (37) and (38), indicating that Chamicuro certainly does have a future tense (note that the definite article cliticizes in (37) but not in (38) beccause in the former, but not the latter, the preceding word ends in a consonant).

$$
\begin{array}{ll}
\text { U-1-yé }=\text { na } & \text { Pámpa Hermosa-šána. } \\
\text { 1-go-FUT=THE(NPST) } & \text { Pampa Hermosa-LOC }
\end{array}
$$

'I will go to Pampa Hermosa.' (ibid:554, 9)

$$
\begin{aligned}
& \text { I-mak-ye?-kána na wá?ni. } \\
& \text { 3-sleep-FUT-PL THE(NPST) tomorrow } \\
& \text { 'They are going to sleep tomorrow.' (ibid:555, 18) }
\end{aligned}
$$

We assume that the lexical description associated with the non-past definite article is the following:

$$
\begin{array}{ll}
n a: & ((\mathrm{GF} \uparrow) \mathrm{TNS})=\mathrm{PRES} \vee \mathrm{FUT} \\
& (\uparrow \mathrm{SPEC})=\mathrm{DEF}
\end{array}
$$

This states that the value of TNS in the f-structure containing the f-structure of the definite article is either PRES or FUT. In the absence of further specification of tense by the verb, there will be two minimal solutions to the f-description (one with the value PRES and one with the value FUT). On the other hand, in an example such as (37) the verb bears future tense morphology specifying ( $\uparrow$ TNS) $=$ FUT and then the f-structure of the clause must satisfy the set of constraints shown in (40). Since a disjunctive f-description is satisfied if one of the disjuncts

eventually percolate up to a higher node". The other option he suggests - that the tensed articles “ 'agree' with some clause-level tense morpheme" is implausible since there is frequently no other tense morpheme in the clause for them to agree with. 
is satisfied, these constraints are satisfied by the (partial) f-structure in (42), which results from the NP in the c-structure in (41).
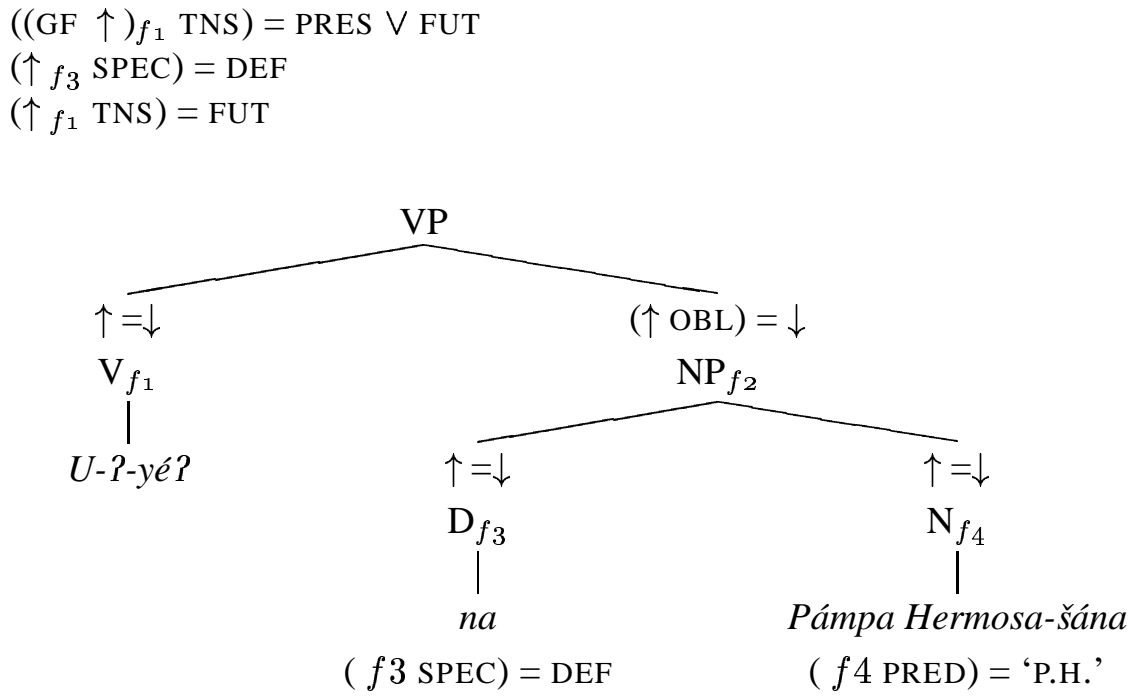

$$
f_{1}\left[\begin{array}{ll}
\text { TNS } & \text { FUT } \\
\text { OBL } & f_{2, f_{3}, f_{4}}\left[\begin{array}{cc}
\text { SPEC } & \text { DEF } \\
\text { CASE } & \text { LOC } \\
\text { PRED } & \text { 'P.H.' }
\end{array}\right]
\end{array}\right]
$$

This approach to the interaction between clausal TAM properties expressed on the verbal head, and those encoded on (nominal) dependents can be straightforwardly extended to cover the more complicated sorts of interaction such as those found in Kayardild. Recall that in Kayardild, the verbal inflection and the modal case marking on the nominal dependents make independent and interacting contributions to the TAM properties of the clause as a whole. For example in (10) the NEG.POT verbal inflection and M.PROP modal case combine to produce a future inability reading, and in (11) the NEG.POT verbal inflection and the M.LOC modal case combine to produce a past inability reading. In the examples below, the M.OBL (43) combines with the verbal APPR (apprehensive) inflection to mark an undesirable event; in (44) the M.PROP places the unpleasant event in the future while the M.LOC in (45) marks it as 'instantiated' and therefore taking place in the present (see Evans 1995 for extended discussion of the independent contribution of verbal inflection and modal case).

(43) warrjawarri ngada barrbiru-tha manarr-iy, kurri-nyarra slowly.NOM 1SG.NOM lift-ACT torch-M.LOC see-APPR

ngijin-inj kala-nyarr rabi-nyarr.

1SG.POSS-M.OBL fly-APPR arise-APPR 
'Unhurriedly I lifted the bark torch, in case (the diver birds) should see me and fly off'. (Evans 1995:405, 10-14)

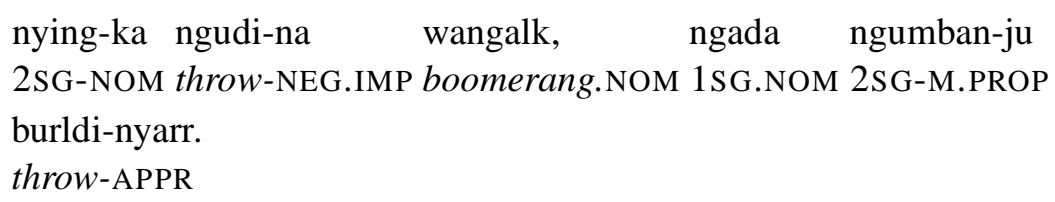

'Don't you throw the boomerang, or I'll throw one at you.'(ibid, 10-15)

(45) thararra kali-nyarra wambal-iya naa-nyarr.

ember.NOM jump-APPR bush-M.LOC burn-APPR

'(Look out), the embers are jumping into the bush, it might burn.' (ibid, 10-16)

Developing a full account of the precise contributions of verbal inflection and modal case marking requires an in-depth analysis of the semantics of tense and modal case marking in Kayardild and thus is outside the scope of the present paper. However, it should be clear that the formalism itself will support an analysis along the lines of Nordlinger and Bresnan's (1996) approach to Wambaya in which the contribution to clausal TAM properties of syntactically independent elements is captured by means of separate but interacting f-structure attributes. For example, the apprehensive verbal suffix in the examples above would contribute modal information of undesirability, and the different modal cases would contribute tense and further specific modal information. Since the tense/mood information contributed by modal case markers will be placed directly into the clausal f-structure, using the constructive morphology approach already demonstrated for Pitta Pitta and Chamicuro, it will interact with that contributed by the verb to define the clausal TAM value as a whole.

Thus, a further advantage to the constructive morphology approach is that it straightforwardly accounts for any agreement or interaction between the tense information associated with the dependent NPs and that of the verb. Since the NP places its tense information into the clausal f-structure directly, then it must be consistent with any information projected from the verb, in order to produce a complete and coherent f-structure. Any clash in values will result in ungrammaticality.

The Chamicuro data illustrates another aspect of nominal TAM marking which we find in a number of languages. This is the fact that nominal TAM is quite often expressible on adjuncts as well as on subjects and complements, as shown in the example (38) above. Unlike complements, adjuncts are not syntactically subcategorised by the predicate and thus occur freely (subject to constraints of semantic compatibility). The fact that clausal temporal information can be encoded on free adjuncts argues against an analysis of temporal specification on dependents under which a verbal head subcategorises for this information, since adjuncts are not subcategorised constituents. In LFG adjuncts are treated 
as (non-subcategorised) members of the set-valued f-structure attribute ADJ for example, the f-structure of (38) is (46) below:

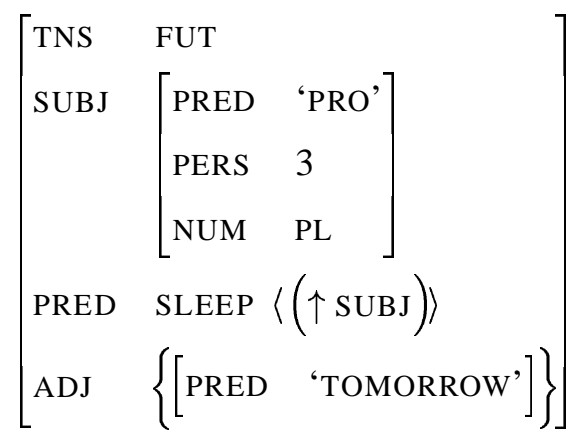

In an f-structure such as (46), the f-structure of tomorrow is not the value of the attribute ADJ in the containing f-structure, but is a member of the set of f-structures which fill the ADJ function. Taking the f-structure of tomorrow to be $\uparrow$, the path out to the largest $\mathrm{f}$-structure in (46) is (ADJ $\in \uparrow$ ). ${ }^{19}$ The presence of (clausal) temporal features on definite articles within ADJ can therefore be straightforwardly accommodated by permitting the inside-out path to the clausal f-structure to allow for an optional $\in$ as attribute. It should be clear that this allows tense information lexically associated with the definite article of an ADJ to contribute this information to the clausal f-structure which contains the ADJ, as well as continuing to allow for tense marked on dependents other than adjuncts. With this extension, (47) replaces (32) and (39) as our generalisation concerning the expression of TAM by definite articles in Chamicuro:

$$
\begin{array}{ll}
k a: & ((\mathrm{GF}(\in) \uparrow) \mathrm{TNS})=\mathrm{PAST} \\
& (\uparrow \mathrm{SPEC})=\mathrm{DEF} \\
n a: & ((\mathrm{GF}(\in) \uparrow) \mathrm{TNS})=\text { PRES } \vee \text { FUT } \\
& (\uparrow \mathrm{SPEC})=\mathrm{DEF}
\end{array}
$$

\subsection{Long Distance EfFects}

Our analysis of Chamicuro has demonstrated how the model of constructive morphology can easily account for the use of both argument and adjunct NPs to encode TAM features of the immediately containing clause. In fact, as discussed in section 1, it is possible for clause-level TAM information to be encoded on more deeply embedded NPs as well. In this section we show how these long

\footnotetext{
19 The expression (ADJ $\in \uparrow$ ) refers to the f-structure in which $\uparrow$ appears as a member of the set of ADJuncts (Dalrymple 2001, p. 261).
} 
distance facts can also be incorporated into the present approach through modifying an f-description along the lines of (47) to permit a longer path out from the f-structure of the NP to the closest clausal f-structure.

Recall from section 1 the Supyire examples repeated below, illustrating the clausal mood distinction (declarative vs. non-declarative) encoded by pronominals. $^{20}$

a. Mìi à pa.

I PERF come

'I have come.' (Carlson 1994:152, 1b)

b. Mu a miì kánhá.

You PERF me tire

'You have annoyed me.' (ibid:152, 2b)

a. $\mathrm{Na}$

wì̀.

me.NONDECL look.at

'Look at me.' (imperative) (ibid:154, 7a)

b. Ma taha na fyè e!

you. NONDECL follow my. NONDECL footprints in

'Follow me (lit. in my tracks), please!' (polite com.) (ibid:522, 8a)

c. Na cevoo `ykùu, taá ma kéćgé ke?

my.NONDECL friend chicken where you. NONDECL go.IMPV LOC.Q

'My friend chicken, where are you going?' (ibid, 7c)

This mood distinction encoded in pronominals is completely independent of other TAM systems in the language (which generally involve the use of auxiliaries as in (12a), see Carlson (1994, p. 307ff) for discussion), and is only encoded morphologically in the choice of pronominal form. Given that these mood-inflected nominals appear in a variety of grammatical functions, we can associate with them lexical descriptions analogous to those for Chamicuro definite articles in (32). Partial lexical entries for non-declarative $m a$ and declarative $m u$ are given below (we will further specify these shortly). Note that the mood information in the latter case is optional since these pronouns can also occur in nondeclarative clauses, as in (52).

$$
\begin{aligned}
m a: & (\uparrow \mathrm{PRED})=\text { 'PRO’ } \\
& (\uparrow \mathrm{PER})=2 \\
& (\uparrow \mathrm{NUM})=\mathrm{SING} \\
& ((\mathrm{GF}(\in) \uparrow) \mathrm{MOOD})=\text { NONDECL }
\end{aligned}
$$

\footnotetext{
${ }^{20}$ Supyire is not an isolated case of mood-inflected pronominals - a similar phenomenon is found in /Gui where the imperative mood of the clause is encoded only by the form of the subject pronominal (Hitomi Ono, pc, see Nordlinger and Sadler (2002)).
} 
$m u: \quad(\uparrow$ PRED $)=$ 'PRO'

$$
\begin{aligned}
& (\uparrow \mathrm{PER})=2 \\
& (\uparrow \mathrm{NUM})=\mathrm{SING} \\
& (((\mathrm{GF}(\in) \uparrow) \mathrm{MOOD})=\mathrm{DECL})
\end{aligned}
$$

(52) Yì̀ fyàhà!

you.PL be.quiet

'Be quiet!' (Carlson 1994:523, 11a)

The interesting twist provided by Supyire, however, is that examples such as (49b) and (49c) above show that the pronominal expressing mood information may be quite deeply embedded in the clause: in (49b) a possessor within an oblique phrase is in non-declarative form, as is a possessor embedded within a vocative function in $(49 \mathrm{c})$. Examples such as these suggest that the relevant condition on the distribution of mood-inflected pronominals in Supyire is a clausebounded condition, that is, they contribute mood information to the clause that they occur in, irrespective of how deeply embedded within that clause they are. The powerful and flexible language of f-descriptions in LFG provides a simple and straigthforward way of capturing the contribution of clausal properties by Supyire pronouns. The use of functionally uncertain (inside-out) constraints will permit pronouns deeply embedded within sentences to (directly) contribute properties to f-structures which enclose them (the notion of uncertainty equations was introduced in section 2.1). Thus the Kleene plus in (53) stands for a disjunction of path extensions, each of which includes at least one GF, allowing for the possibility that the path 'upwards' includes more than one attribute. ${ }^{21}$ The combination of a functionally uncertain constraint with an off-path restriction will then restrict the path 'upwards' to a single clause. The full lexical entry for the non-declarative pronoun $m a$ is provided in (53).

$$
\begin{aligned}
m a: & (\uparrow \mathrm{PRED})={ }^{\prime} \mathrm{PRO} ’ \\
& (\uparrow \mathrm{PER})=2 \\
& (\uparrow \mathrm{NUM})=\mathrm{SING} \\
& \left(\left(\mathrm{GF}^{+}(\in) \uparrow\right) \text { MOOD }\right)=\text { NONDECL } \\
& \neg(\rightarrow \mathrm{SUBJ})
\end{aligned}
$$

The last constraint in (53) states that the pronominal contributes nondeclarative MOOD information to some containing f-structure (recall that the uncertainty statement picks out a set of containing f-structures), where the path up is itself subject to an additional requirement, that no f-structure on the path may contain a SUBJ attribute. This effectively ensures that the MOOD information is

\footnotetext{
${ }^{21}$ Inside-out functional uncertainty is defined as follows:

$(\alpha f) \equiv g$ if and only if $g$ is an f-structure, $\alpha$ is a set of strings, and for some $s$ in the set of strings $\alpha,(s f) \equiv g$ (Dalrymple 2001, p. 145).
} 
contributed to the minimal complete nucleus, that is, to the closest enclosing f-structure containing a SUBJ. Thus, the restriction permits the pronoun to add MOOD $=$ NONDECL to $f 2$ but not to $f 1$ in (54). ${ }^{22}$

$$
f_{1}\left[\begin{array}{ll}
\text { GF } & f_{2}\left[\begin{array}{ll}
\text { SUBJ } & \cdots . .
\end{array}\right]
\end{array}\right]
$$

The use of off-path constraints to state restrictions on solutions to functionally uncertain constraints in this manner is well established in LFG and in particular it is used extensively in Dalrymple (1993) which develops a lexicalized analysis of anaphoric binding conditions. Dalrymple formulates a number of f-structure domains by means of off-path constraints, including the Minimal Complete Nucleus (used in (53) above to express the clausal restriction) and the Minimal Finite Domain (in which the path 'upwards' cannot pass through an f-structure containing a TENSE attribute).

The constrained functional uncertainty statement in (53) therefore ensures that even a pronominal deeply embedded within the clause - such as the possessor NP embedded within the oblique NP in (49b) - can contribute mood information to the clausal f-structure, but, crucially, to no higher containing f-structure. With the same basic constructive morphology analysis, therefore, we can provide a simple and uniform analysis for the encoding of TAM information on dependent NP constituents, irrespective of how deeply they may be embedded in the clause.

\subsection{Multifunctionality}

In the languages we have discussed so far, the TAM distinction encoded on NPs is only encoded on dependent NPs; that is, NPs functioning as arguments or adjuncts. In some languages however, such TAM marking can also be found encoded on NP predicates of verbless clauses. The challenge posed by these languages is that an analysis of the TAM encoded on dependent NPs also needs to be able to account for the use of the same TAM markers on NPs functioning as clausal heads.

This is the situation we find in Sirionó, where NPs are inflected with clausal TAM when functioning as either clausal dependents (55) or predicates of verbless clauses (56) (the following examples are from Firestone (1965, pp. 24-38)). Note that we follow Firestone's careful study of Sirióno morphology and phonology in treating these TAM markers as affixes rather than clitics or particles.

$$
\text { a. Ési-ke óso ñá ií-ra. }
$$

woman-PST go near water-to(LOC)

'The woman went near the water.'

\footnotetext{
${ }^{22}$ We additionally assume that the MOOD attribute is only appropriate for f-structures corresponding to verbal projections.
} 
b. Áe osó-ke-rv ií-rv.

he go-PAST-PERF water-PERF

'He went to the water.'

c. jýkv-ke úke-rv.

tiger-PST sleep-PERF

'The tiger slept.'

(56) a. Néḑa-he-rae.

road-REFL-FUT

'It will be a road.'

b. Kib̧áe-rv.

man-PERF

'It was a man'

c. áe jv́ku-ke-rv

he turkey-PST-PERF

'He was a turkey'

This data demonstrates that the TAM inflections used with NPs, while maintaining the same basic function of encoding clausal temporal and aspectual properties, may do so in two distinct syntactic contexts: when the f-structure of the NP is embedded within the clausal f-structure (i.e. when the NP is a dependent of the clause), and when the f-structure of the NP is the same as the clausal f-structure (i.e. when the NP is the head of the clause). Moreover, the examples in (56) clearly demonstrate that these nominals can be inflected with clausal TAM information without the presence of a verb with which they could be agreeing.

On the current approach this data follows very naturally; we simply assume that the lexical descriptions associated with the TAM markers only optionally specify a grammatical function in the inside-out path, as follows:

$$
\begin{array}{ll}
-k e: & (((\mathrm{GF}) \uparrow) \mathrm{TNS})=\mathrm{PAST} \\
-r v: & (((\mathrm{GF}) \uparrow) \mathrm{ASP})=\mathrm{PERF} \\
-r a e: & (((\mathrm{GF}) \uparrow) \mathrm{TNS})=\mathrm{FUT}
\end{array}
$$

Each of these statements is disjunctive - for example the first statement abbreviates the set of possibilities shown in (58) below:
a. $(\uparrow \mathrm{TNS})=\mathrm{PAST}$
b. $\quad((\mathrm{GF} \uparrow) \mathrm{TNS})=\mathrm{PAST}$

(58a) specifies the f-structure corresponding to the past tense inflected word $(\uparrow)$ as TNS = PAST; when attached to the (predicate) nominal 'turkey' it describes the f-structure given in (59). (58b), on the other hand, describes the 
use with dependent NPs exactly as we have already seen for Chamicuro above. Thus, when attached to the (non-predicative) nominal 'turkey' it describes the f-structure in (60). In each of these f-structures, $f_{1}$ is the f-structure of the NP itself.

$$
\begin{aligned}
& f_{1}\left[\begin{array}{ll}
\text { TNS } & \text { PAST } \\
\text { PRED } & \text { 'TURKEY }\langle(\uparrow \text { SUBJ })\rangle
\end{array}\right]
\end{aligned}
$$

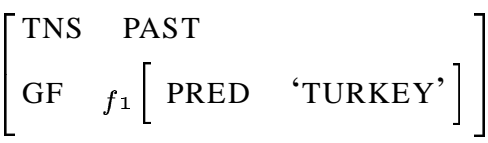

Notice that when attached to NP predicates, TAM markers in this analysis carry exactly the same information as when they attach to verbs (e.g. $(\uparrow$ TNS $)=$ PAST), thus capturing the obvious equivalence in function.

Independent principles governing the distribution of grammatical functions will ensure that the information suitable for dependent NPs (58b) cannot be associated with NPs in predicate function. This option specifies that the NP has a grammatical function in a higher f-structure (see (60)), but there will be nothing licensing this grammatical function in the higher f-structure (since the NP is the clausal predicate itself in this scenario), and so the structure will be ruled ungrammatical by the general principle of coherence.

In order to ensure that the option suitable for NP predicates (58b) is not associated with dependent NPs we simply assume that there is a constraint over the mapping between morphology and syntax which ensures that TAM features must always belong to the clausal f-structure - the minimal complete nucleus (Falk, 2001, p. 182). Since the minimal complete nucleus must necessarily have a subject, this will rule out associating the information in (58b) with a dependent NP, but allow it with an NP predicate, whose f-structure does contain a SUBJ (see (59)).

\subsection{HEAD INCORPORATION}

The analysis presented here treats TAM-marking on dependents by associating an inside-out functional description with the tense marked element which directly attributes the tense information to a dominating f-structure. A further interesting possibility is that the analysis presented here may extend to cover what are at first sight quite independent and different data. Broadly speaking, these are cases where it may be that a finite element, the head of the clause, has incorporated morphologically into a clausal dependent, that is, cases of true head incorporation (rather than just incorporation of features of the head).

One such possible case is the phenomenon of so-called 'floating inflection' in Polish. The past tense is expressed in Polish by means of a $l$ form participle (which inflects for gender) in combination with a finite bound form which bears 
subject agreement features (and may be the sole expression of the subject). This element may appear attached to the participial form, and a past tense paradigm might be given as in Table II (Spencer 1991, p. 370, table 9.9).

Table II. Past Tense of $d a c ́$ 'give'

\begin{tabular}{|l|lllll|}
\hline & $\begin{array}{l}\text { Sing } \\
\text { Masc }\end{array}$ & Fem & Neut & $\begin{array}{l}\text { Plur } \\
\text { Masc }\end{array}$ & Fem/Neut \\
\hline 1 & dałem & dałam & - & daliśmy & datyśmy \\
2 & dałeś & dałaś & - & daltyście & daltyście \\
3 & dał & dała & dało & dali & daty \\
\hline
\end{tabular}

Intriguingly, this bound form can be combined either with the participle (as shown above) or may appear attached to an element to the left of the verb: note that in the following examples we follow the authors' practice of glossing it with person and number features.

(61) a. Wieczorem czytaliśmy książki evening read-1PL books-ACC

b. Wieczoremśmy czytali książki evening-1PL read books-ACC

c. Książki wieczoremśmy czytali books-ACC evening-1 PL read

d. Książkiśmy wieczorem czytali books-1PL evening read 'In the evening we read books.' (Dziwirek 1998:66, 25)

(62) a. Ty jego widziat-eś. you him see.M.SG-2SG

b. Ty-ś jego widział. you-2SG him see.m.sg

c. Ty jego-ś widziat. you him-2SG see.M.SG

'You saw him' (Borsley and Rivero 1994: 374,2)

What is the nature of this floating element? Spencer (1991) argues that this element is a reduced form of the auxiliary be (reflecting person and number distinctions), providing diachronic evidence for this position, and Borsley and Rivero (1994) analyze it as a 'perfect' auxiliary. Diachronically, it appears that 
the bound auxiliary form was indeed a phonological clitic, part of a periphrastically expressed tense-aspect form in combination with a participle of a relatively familiar sort. If this view of the 'floating element' is correct, then if it is morphologically incorporated into the hosts in (61) and (62), these constitute cases in which what would otherwise be the syntactic head of the clause has been morphologically incorporated into a dependent.

Analyses of the synchronic state of affairs are split on whether to treat this element as a syntactic atom phonologically cliticised, or as a bound form, precisely because of the difficulty in head-driven syntactic frameworks of accommodating the resultant 'headless' construction. For example, Borsley and Rivero (1994) treat the participle-auxiliary combination as syntactically analysable syntactic incorporation of V into Aux and the "floating inflection" as PF (phonological) cliticization of I to the constituent to its left. Dziwirek (1998), on the other hand, treats the auxiliary morphologically. The morphophonological evidence for affixal status is extremely strong, (see Spencer 1991 for a full discussion), and, as Spencer observes, the only evidence against this view is the lack of strong selection of the stem/host by the auxiliary (promiscuous attachment). Indeed, this mix of properties led Booij and Rubach (1987) to argue for a lexical treatment, but keeping the process of word-internal cliticization separate from other word formation processes. The evidence therefore strongly suggests that the combination of host and (subject incorporating) auxiliary is not syntactically transparent. If this is correct, then these data constitute a case in which a head (here, the auxiliary (and subject agreement marker) in the past tense formations) is incorporated into a dependent. Providing an analysis of the precise contribution of both the affixal element and the participial element in the Polish past tense is beyond the scope of this paper, but it should be clear that the flexible nature of the mapping between constituent structure and functional structure in LFG and in particular the use of inside-out constraints will permit an elegant treatment of these sorts of morphological incorporation.

Welsh presents another potential case of head incorporation, but of a rather different nature. Borsley and Jones (2000) discuss some cases in Welsh where finite but verb-less sentences with pronominal subjects are permissible. In Welsh finite clauses the verb is clause initial - in synthetically expressed tenses the finite (auxiliary) verb is followed by the subject and then a VP containing nonfinite forms of any further auxiliaries and the main verb, while finite clauses with synthetically expressed tenses exhibit VSO order. However a copula-less variant of the periphrastic pattern is found with second person singular and plural and first person plural pronominal subjects (in all these cases the final consonant of the missing (present tense) copula form and the initial consonant of the pronoun are the same). The glosses in the following data (in which the verbal properties attributed by Borsley and Jones to the pronominal forms appear in square brackets) are those provided by the authors, and underline the fact that 
the forms in question ( $t i, c h i)$ are simple pronouns, that is, they do not show any morphological evidence of affixation (of a form of the copula).

(63) ti 'n licio sudd oren.

[be+pres]2S PROG like juice orange

'You like orange juice.'

(64) chi ddim yn licio sudd oren.

[be+pres]2PL not PROG like juice orange

'You don't like orange juice.'

Borsley and Jones establishes several crucial facts about these data, which distinguish them from a clipped or fast informal speech phenomenon and in particular from similar forms with full NPs. The diagnostics include control of responsives appropriate for questions with forms of be, form of tag questions, possibilities for fronting constituents, possibility of ellipsis and occurrence in noun clauses (the last is illustrated below):
a. Dw
i'n meddwl ti
'n gwbod
Be.PRES.1SG 1SG-PROG think [be+pres].2SG PROG know
'I think you know.'
b. *Dw i'n meddwl dadi 'n gwbod
Be.PRES.1SG I-PROG think Daddy PROG know
'I think Daddy knowing.'

These data strongly suggest that these forms are subject pronouns carrying tense information. Once again, an analysis of such forms follows straightforwardly from the present approach. As with the Polish auxiliary, these Welsh pronominals would simply specify the tense information for the clause to which they belong, using the now familiar inside-out f-descriptions. ${ }^{23}$

(66) $t i$

$$
\begin{aligned}
& ((\mathrm{SUBJ}) \uparrow) \mathrm{TNS})=\mathrm{PRES} \\
& ((\uparrow \mathrm{PRED})=\text { 'PRO' }) \\
& (\uparrow \mathrm{NUM})=\mathrm{SG} \\
& (\uparrow \mathrm{PER})=2
\end{aligned}
$$

Thus, in addition to providing a simple and unifed account for the encoding of clausal TAM on dependent NPs, this approach also extends naturally to cases of head-incorporation discussed independently in the syntactic literature.

\footnotetext{
23 See Barron (1998) and Sadler (1998) for similar analyses of the non-syllabic variants of English reduced auxiliaries as in He'll be leaving soon.
} 


\section{Discussion and Further Issues}

When nominal dependents inflect for clausal temporal or modal properties, features of the clause typically expressed on the head of the clause are found occurring on non-head elements, in some cases as the sole exponent of the clausal property in question. The LFG account presented in the previous section accommodates this phenomenon in a simple and intuitive manner, exploiting the flexibility of the LFG description language to permit (nominal) dependents to contribute information directly to the f-structure of the clause. A crucial property of the analysis is that it is not necessary to posit intrinsic TAM features for nominal f-structures themselves. The question naturally arises as to how this class of data might be captured in frameworks which adopt a single notion of syntactic head, grounded in the notions of categorial similarity and phrase structure. Unfortunately there has been very little work on the phenomenon of TAM-marked clausal dependents in these frameworks reported in the literature, but we review what there is in this section and make some general remarks.

The most relevant work in the literature is Hale's (1998) albeit brief discussion of tense marking on and within dependent nominals in Lardil and Pitta Pitta. Some basic examples of nominal tense marking in Lardil are given in (3) and repeated here.

a. Ngada bilaa wu-thur ngimbenthar diin-kur 1SG.NOM tomorrow give-FUT 2SG.FOBJ this-FOBJ wangalk-ur.

boomerang-FOBJ

'I'll give you this boomerang tomorrow.' (Klokeid 1976:493)

b. Ngada niwentharr maarn-arr wu-tharr.

1SG.NOM 3SG.NFOBJ spear-NFOBJ give-NFUT

'I gave him a spear.' (ibid:476)

Adopting a configurational model of constituent structure with multiple functional heads, Hale views these cases as a sort of tense concord in which subparts of a constituent or phrase are marked for a feature of the phrase as a whole. As Hale observes, if the structure relevant to tense concord in an example such as (68) is as in (69), as would be expected on the sort of configurational model he adopts, then the spreading of Tense marking onto the nominal constituents should be impossible because the tense marker violates the principle of locality in spreading into the domain of the functional head $\mathrm{K}$.

(68) Ngada were-thur kiin-kur karnan-kur maarn-kur.

ISG.NOM throw-FUT that-FOBJ long-FOBJ spear-FOBJ

'I will throw that long spear.' (Hale 1998:200, 8) ${ }^{24}$

${ }^{24}$ Hale's gloss is changed here from FUT to FOBJ for consistency. 
(69)

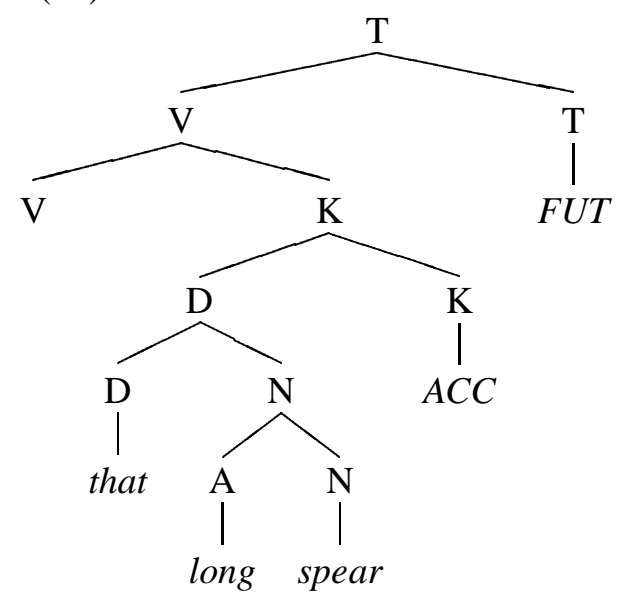

From this perspective, then, what is exceptional about Lardil (and other languages in which tense spreads onto nominal dependents) is that concord is permitted at all. The analysis that Hale suggests is based on the idea that (future) tense marking replaces accusative marking. More specifically, that case and tense are merged in this instance into a single element "If $\mathrm{K}$ and $\mathrm{T}$ were merged in this way, they would not define distinct domains, and the single ending could then be realized in the manner which is normal for Lardil inflections, i.e as suffixed to each head in the relevant domain" (Hale 1998, p. 201). In sum, the mechanism that Hale proposes for tense concord is: attachment of $\mathrm{T}$ to $\mathrm{V}$ and $\mathrm{K}$, fusion by replacement of $\mathrm{K}$ by $\mathrm{T}$ and then subsequent reattachment of the fused $\mathrm{K}-\mathrm{T}$ to the constituents of D.

One difficulty with this analysis is locality. Firstly, the tensed case marking does not always merge with (and therefore replace) the relational case borne by an argument. It 'merges' only with ACC, but crucially it occurs additional to other relational case markers. This is shown in (70) where the future case marker occurs in combination with the instrumental marker.

(70) Ngada marndi-thu niwentha niwen-kur-u

1SG.NOM rob-FUT 3SG.FOBJ 3SG.GEN-INSTR-FOBJ

kerndi-wur-u.

wife-INSTR-FOBJ

'I will steal his wife for him.' (Hale 1997:201)

If a locality violation is "saved" by merger of $\mathrm{T}$ with $\mathrm{K}$, then clearly, this example involves a locality violation. By his own reasoning, this is a violation of locality by entry of $\mathrm{T}$ into the $\mathrm{K}$ domain associated with the instrumental case. Note further the following contrast, in which the ACC spreads onto the higher genitive possessor but not the more deeply embedded. 
(71) kantha-kan-in karnan-in maarn-in father-GEN-ACC long-ACC spear-ACC

'father's long spear' (Hale 1998:198,6)

(72) marun-ngan kantha-kan-in karnan-in maarn-in

boy-GEN father-GEN-ACC long-ACC spear-ACC

'the boy's father's long spear' (Hale 1998:199, 7)

The ACC does not spread, according to Hale, because of a limitation which is a "reflection of the general structural relation of locality" (Hale 1998, p. 199). But note that the degree of locality violation which would be involved if ACC spread to 'boy' in (72) is precisely the same as in (70).

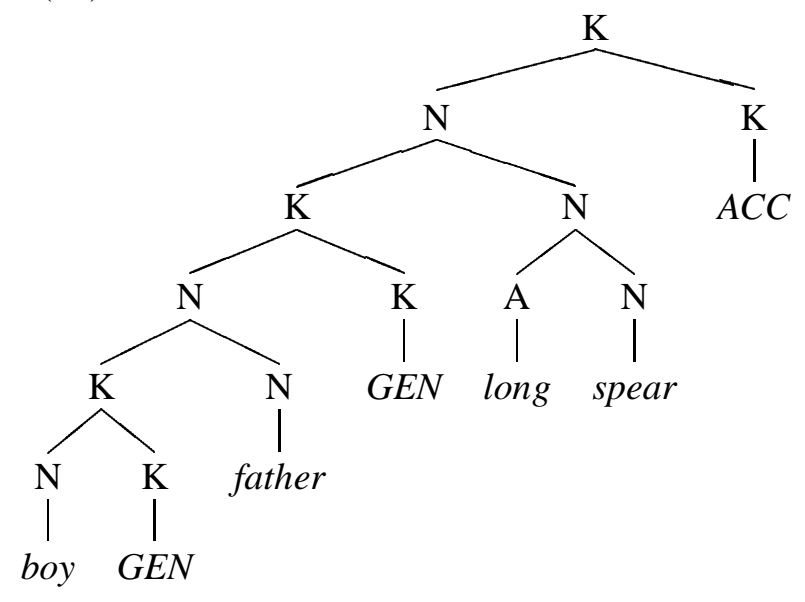

(74)

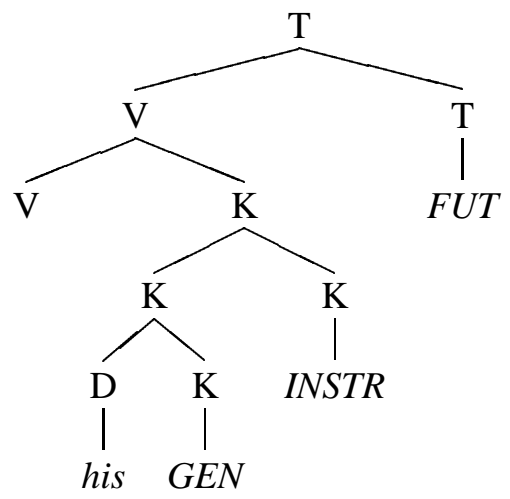

Furthermore, Hale makes explicit reference to a contrast between the spreading of suffixal future tense (illustrated above) and the case marking pattern found with the non-suffixal perfective, which he views as not undergoing spreading (Hale 1998, p. 200), see (75). That this is prefixal rather than suffixal is relevant to Hale, as he observes: "The principle is rather simple, reflecting a universal and 
favored option among languages with suffixal case inflection: attach suffixal $\mathrm{K}$ to the head of the phrase it locally governs, where "head" is each head in the minimal domain locally governed by K" (Hale 1998, p. 198).

(75) Ngada yuurr-were kiin-in karnan-in maarn-in.

ISG.NOM PERF-throw that-ACC long-ACC spear-ACC

'I threw that long spear.' (Hale 1998:200, 8a)

But the problem here is that it is not really clear how on this analysis tense spreading is related to the overt expression forms. Note first that the same accusative marker as occurs in (75) accompanying the prefixal perfective also occurs in combination with the general non-future suffixal inflection on the verb, as shown in (76), which contrasts with the examples in (67).

(76) Ngada niween maarn-in wu-tha.

1SG.NOM 3SG.OBJ spear-OBJ give-GNF

'I gave him a spear.' (Klokeid 1976:476, 56a)

Clearly (67) might be taken to show morphological evidence of "replacement" of accusative case by (both future and non-future) tense. But presumably, on Hale's own assumptions, sentences such as (76) must contain a $\mathrm{T}$ node to constitute a valid sentence. If general non-future (GNF) is $\mathrm{T}$ and suffixal, then on Hale's assumptions, we might expect it to spread. But then -in in (76) would involve T-K merger while -in in (75) would not.

Our own analysis of Lardil instead follows from the constructive morphology approach outlined above. Lardil core argument case marking operates according to a nominative-accusative pattern, thus all three forms exemplified in (76) above introduce accusative case information. Additionally, the form -(w)ur is constrained to occur only in future tensed clauses, and the form -(ng)arr in non-future tensed clauses. The third form, $-(i) n$ is constrained to occur only in clauses which lack a tense specification (this includes aspectually marked perfective clauses, and clauses involving the plain, unmarked verbal inflection $-(\emptyset /- \text { tha }(\mathrm{GNF}))^{25}$

$$
\begin{array}{ll}
-(i) n: & (\uparrow \mathrm{CASE})=\mathrm{ACC} \\
& \neg((\mathrm{OBJ} \uparrow) \mathrm{TNS}) \\
(w) u r: & (\uparrow \mathrm{CASE})=\mathrm{ACC} \\
& ((\mathrm{OBJ} \uparrow) \mathrm{TNS})=_{c} \text { FUT } \\
(n g) a r r: & (\uparrow \mathrm{CASE})=\mathrm{ACC} \\
& ((\mathrm{OBJ} \uparrow) \mathrm{TNS})={ }_{c} \text { NFUT }
\end{array}
$$

\footnotetext{
25 There are several alternative approaches to this data. For example, if GNF IS interpreted as an f-structure TNS value, then the plain accusative must be constrained to occur only where tense is neither FUT nor NFUT, as an alternative to the approach sketched in the text. We leave this open for future research.
} 
The use of constraining equations here (signalled by the subscripted ' $c$ ') captures the fact that these case markers are purely concordial with the verbal tense: that is, they do not define or specify any tense information themselves but are appropriate only for f-structures which are independently specified for tense. The effect of this is to require that the verb is also specified for tense. The model of constructive morphology which we adopt here also deals straightforwardly with the type of long distance concord which results in the stacking of multiple case markers on a single nominals, as in example (70). In an investigation of case stacking phenomena in languages such as Kayardild and Martuthunira, Nordlinger (1998) shows that the iconic ordering exhibited by such stacking morphology motivates a strong constraint on the way morphological information interacts with the syntax encapsulated in the Principle of Morphological Composition (see Nordlinger 1998). Space precludes any detailed discussion of this principle here, but in short the PMC ensures that the "path out" in any inside-out statement associated with a morphological element takes into account whatever f-structure path is defined by more deeply embedded affixes. In this way this principle constrains the interaction of functional descriptions associated with "pieces" of morphology such that each affix contributes information to parts of the f-structure outside of that already specified by the stem to which it is attached.

Thus, when the tensed accusative markers in (77) are affixed to a nominal already inflected with the instrumental case as in (70), for example, the tense and case information associated with the accusative marker will not be relevant to the f-structure of the instrumental nominal itself, but to the higher f-structure belonging to the clause, as appropriate.

In Hale's approach, configurational assumptions are key in ensuring that tense does not spread onto the subject (for Lardil). For languages such as Pitta Pitta which does exhibit tense concordial case morphology on subjects, see examples (78) and (79), Hale adopts a configurational model with the sort of structure in (80), in which the subject is c-commanded by the functional head $\mathrm{T}$ :

(78) Majumpa-lu pukarra-nha thaji-ka kangaroo-ERG grass-ACC eat-PST

'The kangaroo ate the grass' (Hale 1998: 203 ex. 10a) Majumpa-ngu pukarra-nha/-ku thaji
kangaroo-FUT grass-ACC/-ACC.FUT eat.FUT

The kangaroo will eat the grass'(Hale 1998:203 ex. 10b) 


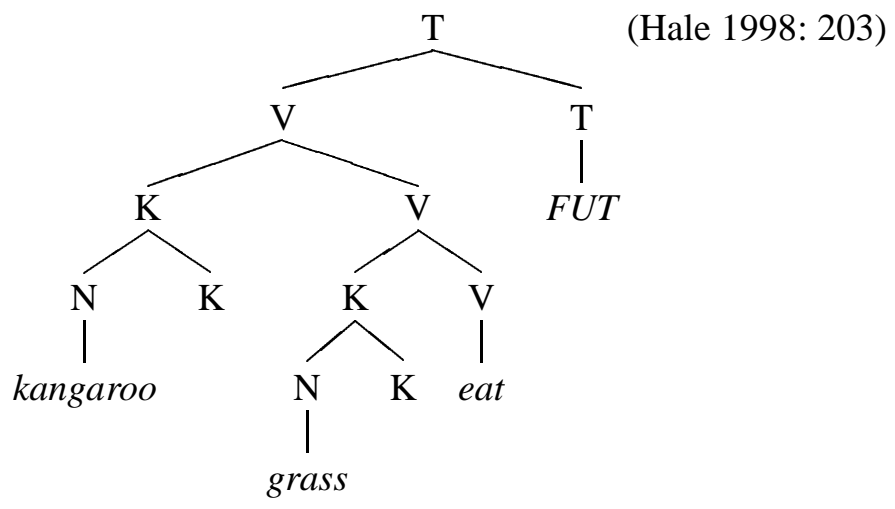

On this configurational view it would be problematic to find languages in which you get TAM marking on the subject but not on the other grammatical functions. But this is precisely what is found in later dialects of Pitta Pitta in which the tense distinctions on objects have been lost, and also in the neighbouring language Wangkajutjuru (Blake, 1979). Elsewhere, the Camerounian language Yạg Dii also has tense and mood inflected subject pronominals, but no TAM marking on other dependents (Bohnhoff, 1986). On the other hand, the constructive analysis of dependent-marked nominal TAM presented in section 2 above allows us to state any restrictions on the grammatical function of the tense-encoding nominal that are empirically motivated.

In a series of two papers Pesetsky and Torrego (2001, to appear) explore the idea that what is known as structural Case (nominative and accusative case on DPs) are actually instances of $\mathrm{uT}$, that is, an uninterpretable Tense feature occurring on D or DP. Uninterpretable features, in this framework, make no semantic contribution to the projection on which they appear, but play a role in triggering syntactic processes (such as movement). An example would be the subject agreement features of a finite verb. The positing of (often invisible) uninterpretable (meaningless) features is a key aspect of the framework Pesetsky and Torrego are working with, and such features are deleted subsequent to pairing up in appropriate fashion with (presumably interpretable) instances of the same feature in appropriate configurational relations (this is referred to as the relation Agree). In Pesetsky and Torrego (2001) they propose that Nominative Case is uninterpretable $\mathrm{T}$ on $\mathrm{D}$, and treat the $\mathrm{T}$ features of DP as strictly uninterpretable, although they do observe in a footnote that DPs can be temporally situated, citing the work on the temporal location of nominals by Enç (1981) and Musan (1995) and the work on Somali determiners by Lecarme (1999).

Pesetsky and Torrego (2001) contains some discussion of a morphological perspective on their unification of the notions of nominative case on DPs and agreement on $\mathrm{T}$, that is, of the notion that nominative is simply an uninterpretable $\mathrm{T}$ feature on D or DP. They note that the crucial covariance evidence (parallel to what you find with subject agreement morphology on a verbal head) 
is lacking: "the morphology of nominative case does not often covary with choice of present, past, or future tense" (Pesetsky and Torrego 2001, p. 365). This is the context in which they discuss Pitta Pitta. For Pitta Pitta they claim that future tense is marked on the nominative subject NP and no other tense is marked on any nominal (although they do note that in earlier stages the language did mark future tense on object nominals as well), giving the following example:

(81) Ngapiri-ngu thawa paya-nha. father-FUT kill bird-ACC

'Father will kill the bird (with missile thrown).'

Recall however from the discussion in section 2.1 that the Pitta Pitta case marking system itself differs according to whether the clause is future tense or not, and further that these distinctions are evident in the case marking found on instrumental NPs as well as on subjects and objects (in some cases). This is shown in the following table, repeated from Table I above.

Table III. Pitta Pitta case/tense suffixes

\begin{tabular}{|l|llll|}
\hline & $\mathrm{S}$ & $\mathrm{A}$ & $\mathrm{O}$ & Inst \\
\hline $\begin{array}{l}\text { Non-Future } \\
\text { Future }\end{array}$ & $-\emptyset$ & $-\mathrm{lu}$ & - nha & - lu \\
\hline
\end{tabular}

In light of this, the claim that only nominative marked NPs reflect tense, and only future tense, would appear untenable. Consider the following examples.

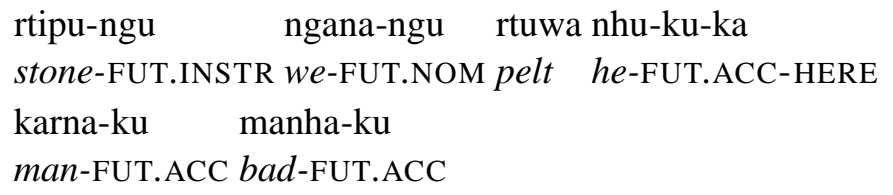

On closer inspection, it is quite unclear what Pesetsky and Torrego mean by stating that future tense is marked on the nominative subject DP in Pitta Pitta - by their own hypothesis, all nominative DPs are uT, and therefore marked for T. If they take all subjects in Pitta Pitta (that is, all S and A arguments) to be nominative, then the claim that only future tense is marked on nominatives makes no sense, for clearly, by hypothesis, all nominatives are uT, and so we 
would expect tense to be marked on nominative subjects in non-future contexts also. If on the other hand, they follow more standard Australianist analysis (reflected in Table III) and take the tense marking system in the future tense to be nominative-accusative based, and that in the non-future tenses to be a three-way system, then it is clearly untrue that the reflection of tense distinctions in the case system is limited to the nominative case! Furthermore, the tense distinctions in the case system are not limited to the nominative, nor even to cases marking core grammatical functions, as the table above makes clear, but occur also on instrumental arguments (and adjuncts to the subject) ((82) and (83)). Clearly, then, tense based allomorphy, contrary to the claim made in Pesetsky and Torrego, is not limited to the nominative, even in the language Pitta Pitta which they discuss. In sum, the logical problem here concerns what might constitute evidence for the uninterpretable feature whose presence they hypothesize: on the one hand, uT is necessarily distinct from morphological expression since it occurs in all languages by hypothesis, but on the other hand they are using the presence of overt morphological expression to support their approach.

In more general terms, it is certainly difficult to see how the deployment of abstract $\mathrm{T}$ features on arguments in the Pesetsky and Torrego framework can offer an account of overt clausal TAM marking on nominal dependents in the range of languages we have discussed above. The essential concerns which underlie the positing of an uT feature on DP (and an iT (interpretable) feature on PP) arguments within this strand of work involve instead the theory of Case of Chomskyan generative approaches and the patterns of complementation. The fact that overt nominal TAM marking is attested on unselected adjuncts and in combination with overt case markers does not seem self-evidently likely to fall within the analytic domain explored in Pesetsky and Torrego's work. For example, the probe for uT on a (nominative) DP subject goal is a hypothesized $\mathrm{T}_{s}$ functional head, and the probe for $\mathrm{uT}$ on an (accusative) DP object is a hypothesized $\mathrm{T}_{o}$ functional head as shown in the verbal predication structure in (84).

$$
\left[\mathrm{SUBJ}_{s}\left[v p v \mathrm{~T}_{o}\left[{ }_{V P} \mathrm{~V} \mathrm{OBJ}\right]\right]\right]
$$

But this itself raises a number of problems. In particular, it is not clear what relations are envisaged between $\mathrm{T}_{s}$ and $\mathrm{T}_{o}$, and between these $\mathrm{Ts}$ and the clausal tense value itself. Furthermore, if the postulation of uT on direct object arguments involves a $\mathrm{T}_{o}$ head, then the occurrence of uT on other arguments and on instrumental adjuncts will require further $\mathrm{T}_{x}$ nodes, one for each tensed marked $\mathrm{NP}$, compounding the difficulty of relating this proliferation of $\mathrm{T}_{x}$ nodes to the actual clausal tense.

In general, then, the existence of nominal tense marking on various sorts of adjuncts and deeply embedded arguments in a variety of languages requires the postulation of further probing heads in the appropriate configuration in this approach. Given the normal locality expectations for probe-goal relations, setting 
up the relationship between a (clausally oriented) functional head and a nominal tense marker deeply embedded within an argument function does not appear to be straightforward. In an interesting discussion of cases of tensed prepositions in Titan (Admirality subgroup, Oceania), Bowern and Aygen-Tosun (2000) explore some of the problems posed by this data for a Minimalist account. In Titan, a subset of the language's prepositions must bear a tense feature which agrees with the tense expressed on what Bowern and Aygen-Tosun describe as the subject agreement clitic which is hosted by the verb. (85) exemplifies this interesting data. Exploring this phenomenon further is beyond the scope of the present paper but the LFG account we present here for dependent-marked nominal TAM can extend naturally to accommodate such tense-marked prepositions in Titan.

$$
\begin{aligned}
& \mathrm{i}=\text { tawi buangan } \mathrm{i}-\mathrm{ti} \quad \text { Manus. } \\
& \text { 3SG.NFUT=place } \text { yams NFUT-on Manus. }
\end{aligned}
$$

'He put yams on the island of Manus.' (Bowern and Aygen-Tosun 2000: ex. 7)

Finally, although we are not aware of any explicit HPSG analysis of the data discussed here, in a paper on case stacking in Australian languages, Malouf (2001) suggests that modal case in Kayardild (see section 1), which appears on all non-subject clausal constituents and, in conjunction with the verb, specifies tense/mood values for the clause as a whole (Evans 1995), could be straightforwardly accounted for by HPSG's Case Concord Principle which he formulates as follows.

$$
\begin{aligned}
& {\left[\begin{array}{ll}
\text { HEAD } \mid \text { CASE } & {[0]} \\
\text { DEPS } & [2] \oplus\langle\text { [ ARG NP [ LCASE [1] list }(\text { case })]]\rangle \oplus[3]
\end{array}\right]} \\
& \overrightarrow{[\text { DEPS }}[2] \oplus\langle[\text { ARG NP [ CASE [1] } \oplus[0]]]\rangle[3]]
\end{aligned}
$$

Thus, on this view, such tense-based case marking on nominals in Kayardild is treated as a form of concord whereby the (verbal) head shares its (modal) case feature with its dependents. Finite verbs in Kayardild, then, have (modal) case features which aren't morphologically expressed on the verb itself, but which spread (via the concord principle) to its list of dependents. There are a number of problems with this approach to modal case. Firstly, modal case crucially doesn't appear on subjects and subject-oriented adjuncts, as shown in the Kayardild examples repeated here from above. The case concord principle simply spreads the modal case feature onto all items of the dependents list, and thus would counterfactually predict that modal case appears on subjects also. 
warrjawarri ngada barrbiru-tha manarr-iy, kurri-nyarra slowly.NOM 1SG.NOM lift-ACT torch-M.LOC see-APPR ngijin-inj kala-nyarr rabi-nyarr. 1SG.POSS-M.OBL fly-APPR arise-APPR

'Unhurriedly I lifted the bark torch, in case (the diver birds) should see me and fly off.' (Evans 1995:405, 10-14)

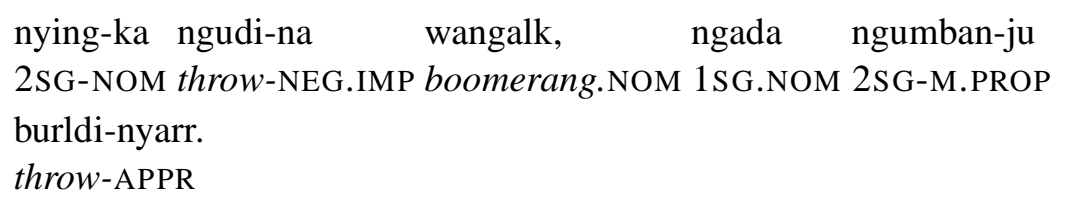

'Don't you throw the boomerang, or I'll throw one at you.'(ibid, 10-15)

(89) thararra kali-nyarra wambal-iya naa-nyarr.

ember.NOM jump-APPR bush-M.LOC burn-APPR

'(Look out), the embers are jumping into the bush, it might burn.' (ibid, 10-16)

Furthermore, this head-driven view of modal case has other undesirable consequences. Firstly, as shown by the examples above, and discussed in detail by Evans (1995), modal case works in conjunction with the verbal TAM inflection to fully define the TAM value for the clause as a whole. On this head-driven approach, however, such interaction is not captured. Rather, each TAM-inflected verb form simply assigns a modal case to its dependents: where one verb form co-occurs with a range of modal case values, multiple lexical entries for the verb need to be posited. Consider, for example, the apprehensive verbal inflection exemplified in the examples above. On the head-driven view the lexicon will be proliferated to contain three different lexical entries for each verb that can be inflected with the apprehensive suffix: one which spreads the modal oblique case as in (87); one which spreads the modal proprietive case, as in (88); and one which spreads the modal locative, as in (89). Each of these apprehensiveinflected verbs will have a slightly different TAM semantics, but the relationship between the modal case value spread to the dependents and the TAM semantics of the verb will be entirely coincidental; the generalization that the modal case value and the verbal TAM work together to fully specify the TAM value of the clause will remain uncaptured.

Additionally, it is not clear how this approach to TAM-inflected dependent nominals would extend to the other languages we have discussed, where there is no modal case feature to be spread. One possibility would be to treat the phenomenon as a form of tense concord, whereby the dependent nominals carry tense features in agreement with the verb which subcategorises for them. Such an approach may be reasonable where we do seem to have pure tense agreement morphology, that is, in cases where a nominal dependent of a verbal head is marked to agree with some TAM feature of the verbal head, such as in Lardil 
(see above). But positing intrinsic TAM features for nominal dependents of verbal heads does not capture the intuition concerning the data discussed here, in which the nominal elements directly co-describe or constrain the TAM values of the clause (or verbal projection) within which they appear. Furthermore, in some languages, such as Supyire and Chamicuro, the relevant distinction is not encoded on the verb at all making a concord analysis seemingly untenable.

\section{Conclusion}

This paper has presented an analysis of a little discussed phenomenon, that of clausal tense, aspect and mood marking occurring on nominals and other dependents. Building on previous work we have shown how a simple and intuitively appealling account of this phenomenon can be given in the lexicalist, constraintbased theory of LFG, using the model of constructive morphology developed within that framework. When clausally-interpreted tense, aspect and mood information is expressed morphologically on nouns and determiners what we have is a mismatch between the morphological expression of these properties and the domain within which they are interpreted: such nominals and determiners are morphologically tensed without themselves being temporally located by the tense marking, which is semantically interpreted with respect to the clause. The core of our analysis is the association of inside-out constraints with morphological formatives, which permits inflected words to contribute information not just to their own f-structures, but directly to the f-structures which contain them. A crucial advantage of the present approach emerges in the treatment of TAM marking on deeply embedded arguments, where our approach permits a direct relation to be stated between the morphological formative and the clausal $\mathrm{f}$ structure within which it is (deeply) embedded, without the need for featural information to be passed up and down head chains. A further advantage of our approach emerges in consideration of (potentially long-distance) TAM marking which is restricted to certain categories of word, for example, Supyire mood marking, which is morphologically realized only on pronominals. If this relation is seen as a chain of local head-dependent relations, then it would be necessary to postulate mood distinctions as intrinsic featural properties of dependents which never overtly realize these properties. This is unnecessary on our approach. Finally, the inside-out approach extends gracefully to accommodate the existence of TAM marking on a variety of adjuncts (e.g. in Pitta Pitta, Kayardild and Chamicuro), without requiring any special mechanisms or alterations in our syntactic approach to adjuncts.

c044ns.tex; 27/11/2003; 11:15; p.39 


\section{References}

Aikhenvald, Alexandra Y. To appear, The Tariana language of Northwest Amazonia. Cambridge: Cambridge University Press.

Andrews, Avery: 1996, 'Semantic case-stacking and inside-out unification'. Australian Journal of Linguistics 16(1), 1-55.

Barron, Julia: 1998, 'have' contraction: explaining 'trace effects' in a theory without movement'. Linguistics 36(2), 223-251.

Barron, Julia: 2000, 'The morphosyntactic correlates of finiteness'. In: M. Butt and T. H. King (eds.): Proceedings of LFG00. Stanford, CA, pp. 25-43, CSLI Publications: http://wwwcsli.stanford.edu/publications.

Bender, Emily and Ivan Sag: 2001, 'Incorporating contracted auxiliaries in English'. In: R. Cann, C. Grover, and P. Miller (eds.): Grammatical Interfaces in HPSG. Stanford, CA: CSLI Publications, pp. 17-32.

Blake, Barry: 1979, 'Pitta Pitta'. In: R.M.W. Dixon and Barry Blake (ed.): Handbook of Australian Languages Volume 1. Amsterdam: Benjamins, pp. 183-242.

Bohnhoff, Lee. E.: 1986, 'Yạg Dii (Duru) Pronouns'. In: U. Wiesemann (ed.): Pronominal Systems. Tübingen: Gunter Narr Verlag, pp. 103-129.

Booij, Geert and Jerzy Rubach: 1987, 'Postcyclic versus Postlexical Rules in Lexical Phonology'. Linguistic Inquiry 18, 1-44.

Borsley, Robert. and Bob M. Jones: 2000, 'Copula-less sentences in Welsh'. Unpublished presentation, 7th Gregynog Welsh Syntax Seminar.

Borsley, Robert and Maria L. Rivero: 1994, 'Clitic Auxiliaries and Incorporation in Polish'. Natural Language and Linguistic Theory 12(4), 373-422.

Bowern, Claire and Gülsat Aygen-Tosun: 2000, 'Titan's Tensed Prepositions'. In: Papers from the 36th CLS, Vol. 2. pp. 35-48.

Bresnan, Joan (ed.): 1982, The Mental Representation of Grammatical Relations. Cambridge, MA: MIT Press.

Bresnan, Joan: 2001, Lexical Functional Syntax. Oxford: Blackwell.

Bresnan, Joan and Sam Mchombo: 1987, 'Topic, pronoun and agreement in Chicheŵa'. Language 63, 741-82.

Bresnan, Joan and Sam A. Mchombo: 1995, 'The Lexical Integrity Principle: Evidence from Bantu'. Natural Language and Linguistic Theory 13(2), 181-254.

Butt, Miriam: 1995, The Structure of Complex Predicates in Urdu. Stanford, CA: CSLI Publications.

Bybee, Joan L.: 1985, Morphology. Amsterdam: John Benjamins.

Carlson, Robert: 1994, A Grammar of Supyire. Berlin: Mouton de Gruyter.

Culy, Christopher: 1990, 'The syntax and semantics of internally-headed relative clauses'. Ph.D. thesis, Stanford University, Stanford, CA.

Dalrymple, Mary: 1993, The Syntax of Anaphoric Binding. Stanford,CA: CSLI Publications.

Dalrymple, Mary: 2001, Lexical Functional Grammar. San Diego, CA: Academic Press.

Dalrymple, Mary, Ron Kaplan, John Maxwell, and Annie Zaenen (eds.): 1995, Formal Issues in Lexical Functional Grammar. Stanford, CA: CSLI Publications.

Dziwirek, Katarzyna: 1998, 'Reduced Constructions in UG: Evidence from Polish Object Control Constructions'. Natural Language and Linguistic Theory 16(1), 53-99.

Enç, Murvet: 1981, 'Tense without Scope: An Analysis of Nouns as Indexicals'. PhD Dissertation, University of Wisconsin, Madison, WI.

Evans, Nicolas: 1995, A Grammar of Kayardild: With Historical-Comparative Notes on Tangkic. Berlin: Mouton de Gruyter.

Evans, Nicolas: 2003, 'Typologies of Agreement: some problems from Kayardild'. Transactions of the Philological Society 101(2), 203-234. 
Evans, Nicolas: To appear , A Pan-dialectal Grammar of Bininj Gun-Wok (Arnhem Land): Mayali, Kunwinjku and Kune. Canberra: Pacific Linguistics.

Falk, Yehuda: 2001, Lexical-Functional Grammar: An Introduction to Parallel Constraint-Based Syntax. Stanford, CA: CSLI Publications.

Firestone, Homer L.: 1965, Description and Classification of Sirionó. London: Mouton.

Haegeman, Liliane: 1994, Introduction to Government and Binding Theory. Oxford: Blackwell.

Hale, Ken: 1997, 'Remarks on Lardil phonology and morphology'. In: Ngakulmungan Kangka Leman (ed.): Lardil Dictionary. Queensland, Australia: Mornington Shire Council, pp. 1256.

Hale, Ken: 1998, 'On endangered languages and the importance of linguistic diversity'. In: L. A. Grenoble and L. J. Whaley (ed.): Endangered languages: Language loss and community response. Cambridge: Cambridge University Press, pp. 192-216.

Halvorsen, Per-Kristian and Ron M. Kaplan: 1988, 'Projections and Semantic Description in Lexical-Functional Grammar'. In: Proceedings of the International Conference on Fifth Generation Computer Systems. Tokyo, pp. 1116-1122.

Kaplan, Ron and Joan Bresnan: 1982, 'Lexical Functional Grammar: a Formal System for Grammatical Representation'. In: J. Bresnan (ed.): The Mental Representation of Grammatical Relations. Cambridge, MA: MIT Press, pp. 173-282.

King, Tracy. H.: 1995, Configuring Topic and Focus in Russian. Stanford, CA: CSLI Publications.

Klokeid, Terry: 1976, 'Topics in Lardil Grammar'. Ph.D. thesis, MIT, Boston, MA.

Lecarme, Jacqueline: 1999, 'Nominal Tense and Tense Theory'. In: F. Corblin, C. DobrovieSorin, and J.-M. Marandin (eds.): Empirical Issues in Formal Syntax and Semantics 2. The Hague: Thesus, pp. 333-354.

Lee, Hanjung: 1999, 'Aspectual and thematic licensing of grammatical case'. In: S. Billings, J. Boyle, and A. Griffith (eds.): Papers from the 35th CLS. pp. 203-222.

Lehmann, Christian and Edith Moravcsik: 2000, 'Noun (Article 73)'. In: G. Booij, C. Lehmann, and J. Mugdan (eds.): Morphologie/Morphology. Berlin: Mouton de Gruyter, pp. 732-757.

Malouf, Rob: 2001, 'A head-driven account of long-distance case assignment'. In: R. Cann and C. Grover and P. Miller (ed.): Grammatical Interfaces in HPSG. Stanford, CA: CSLI Publications, pp. 201-14.

Mohanan, Tara: 1995, 'Wordhood and lexicality: noun incorporation in Hindi'. Natural Language and Linguistic Theory 13(1), 75-134.

Musan, Renate: 1995, 'On the temporal interpretation of noun phrases'. Ph.D. thesis, MIT, Boston, MA.

Nordlinger, Rachel: 1998, Constructive Case: Evidence from Australian Languages. Stanford, CA: CSLI Publications.

Nordlinger, Rachel and Joan Bresnan: 1996, 'Nonconfigurational tense in Wambaya'. In: M. Butt and T. H. King (eds.): Proceedings of LFG96. Stanford, CA, pp. 1-15, CSLI Publications: http://www-csli.stanford.edu/publications.

Nordlinger, Rachel and Louisa Sadler: 2000, 'Tense as a Nominal Category'. In: M. Butt and T. H. King (eds.): Proceedings of LFG00. Stanford, CA, pp. 197-214.

Nordlinger, Rachel and Louisa Sadler: 2002, 'The Typology of Nominal Tense'. Under review.

O'Connor, Rob: 2002, 'Clitics and Phrasal Affixation in Constructive Morphology'. In: M. Butt and T. H. King (eds.): Proceedings of LFG02. Stanford, CA, pp. 315-332, CSLI Publications: http://www-csli.stanford.edu/publications.

Ørsnes, Bjarne: 2002, 'Case marking and Subject Extraction in Danish'. In: M. Butt and T. H. King (eds.): Proceedings of LFG02. Stanford, CA, pp. 333-353, CSLI Publications: http://www-csli.stanford.edu/publications.

Parker, Steve: 1999, 'On the behavior of definite articles in Chamicuro'. Language 75(3), 552562. 
Pesetsky, David and Esther Torrego: 2001, 'T-to-C Movement: Causes and Consequences'. In: M. Kenstowicz (ed.): Ken Hale: A Life in Language. Boston, MA: MIT Press, pp. 355-426.

Pesetsky, David and Esther Torrego: To appear, 'Tense, Case and the Nature of Syntactic Categories'. In: J. Guéron and J. Lecarme (ed.): The Syntax of Time. Boston, MA: MIT Press.

Pinker, Steven and Paul Bloom: 1990, 'Natural Language and Natural Selection'. Brain and Behavioral Sciences 13, 707-784.

Sadler, Louisa: 1998, 'English Auxiliaries as Tense Inflections'. Essex Research Reports in Linguistics 24, 1-16.

Sadler, Louisa and Rachel Nordlinger: 2003, 'Case Stacking in Realizational Morphology'. under review.

Sells, Peter: 2000, 'Negation in Swedish, where it's not at'. In: M. Butt and T. H. King (eds.): Proceedings of LFG00. Stanford, CA, pp. 244-263, CSLI Publications: http://wwwcsli.stanford.edu/publications.

Sharma, Divyana: 1999, 'Nominal clitics and constructive morphology in Hindi'. In: Proceedings of LFG99. Stanford, CA, pp. 1-21, CSLI Publications: http://wwwcsli.stanford.edu/publications.

Simpson, Jane: 1983, 'Aspects of Warlpiri Morphology and Syntax'. Ph.D. thesis, MIT, Boston, MA.

Simpson, Jane: 1991, Warlpiri Morpho-Syntax. Dordrecht: Kluwer Academic Publishers.

Spencer, Andrew: 1991, Morphological Theory. Oxford: Blackwell.

Stump, Greg: 2001, Inflectional Morphology. Cambridge: CUP.

Received 2 April 2003

Revised 10 September 2003

Rachel Nordlinger

Department of Linguistics and Applied Linguistics

University of Melbourne

Victoria 3010

Australia

$<$ racheln@unimelb.edu.au $>$

Louisa Sadler

Department of Language and Linguistics

University of Essex

Wivenhoe Park

Colchester CO4 3SQ

U.K.

<louisa@essex.ac.uk > 